\title{
Asymmetric Copolymers: Synthesis, properties and applications of gradient and other partially segregated copolymers.
}

Junliang Zhang, ${ }^{1,2,3}$ Barbara Farias-Mancilla, ${ }^{4}$ Mathias Destarac, ${ }^{4}$ Ulrich S. Schubert, ${ }^{2,3}$

Daniel J. Keddie, ${ }^{* 5}$ Carlos Guerrero-Sanchez, ${ }^{* 2,3}$ and Simon Harrisson ${ }^{* 4}$

${ }^{1}$ MOE Key Laboratory of Material Physics and Chemistry under Extraordinary Conditions, Shaanxi Key Laboratory of Macromolecular Science and Technology, Department of Applied Chemistry, School of Science, Northwestern Polytechnical University, Xi'an, Shaanxi, 710072, P.R. China.

${ }^{2}$ Laboratory of Organic and Macromolecular Chemistry (IOMC), Friedrich Schiller University Jena, Humboldtstr. 10, D-07743 Jena, Germany;

${ }^{3}$ Jena Center for Soft Matter (JCSM), Friedrich Schiller University Jena, Philosophenweg 7, D-07743 Jena, Germany;

${ }^{4}$ Laboratoire des IMRCP, Université de Toulouse, CNRS UMR 5623, Université Paul Sabatier, 118 route de Narbonne, 31062 Toulouse Cedex 9, France;

${ }^{5}$ School of Sciences, Faculty of Science \& Engineering, University of Wolverhampton, Wulfruna Street, Wolverhampton WV1 1LY, United Kingdom

*Correspondence to: E-mail: d.keddie@wlv.ac.uk; carlos.guerrero.sanchez@uni-jena.de; polyharrisson@gmail.com;

\begin{abstract}
Asymmetric copolymers are a class of materials with intriguing properties. They can be defined by a distribution of monomers within the polymer chain that is neither strictly segregated as in the case of block copolymers nor evenly distributed throughout each chain as in the case of statistical copolymers. This definition includes gradient copolymers, as well as block copolymers that contain segments of statistical copolymer. In this review, different methods to
\end{abstract}


synthesize asymmetric copolymers are firstly discussed. The properties of asymmetric copolymers are investigated in comparison to those of block and random counterparts with similar composition. Finally some examples of applications of asymmetric copolymers, both academic and industrial, are demonstrated. The aim of this review is to provide a perspective on the design and synthesis of asymmetric copolymers with useful applications.

\section{Abbreviations index}

3HT 3-hexylthiophene

3BrHT 3-(6-bromohexyl) thiophene

AA Acrylic acid

AFM Atomic force microscopy

ATRP Atom transfer radical polymerization

CMC Critical micelle concentration

$\mathrm{CP} \quad$ Cloud point

DPPS 4-(Diphenylphosphino)styrene

EGMA Ethylene glycol methyl ether methacrylate

FPMI Furan-protected $N$-propyl-maleimide

LCST Lower critical solution temperature

LRP Living radical polymerization

MMA Methyl methacrylate

nBA $\quad n$-butyl acrylate

NMP Nitroxide-mediated polymerization

OMRP Organometallic-mediated radical polymerization

PES Poly(ether sulfone)

RAFT Reversible addition-fragmentation chain transfer

RDRP Reversible deactivation radical polymerization 
ROMP Ring-opening metathesis polymerization

SAXS Small-angle X-ray scattering

SCFT Self consistent field theory

$\mathrm{scCO}_{2} \quad$ Supercritical carbon dioxide

Sty Styrene

$T_{\mathrm{g}} \quad$ Glass transition temperature

XPS X-ray photoelectron spectroscopy

\section{Introduction}

If two monomers are mixed together and polymerized, they will form a statistical copolymer. The same two monomers, polymerized separately and joined together, give a block copolymer. While the properties of the statistical polymer are intermediate between those of the respective homopolymers, the block copolymer presents properties of both homopolymers, as well as emergent properties that are present in neither homopolymer.

Block and statistical copolymers represent two extremes in the distribution of monomers within a copolymer. Between these extremes there is a spectrum of structures in which the different types of monomer are neither completely separated, as in block copolymers, nor statistically distributed in a manner that is independent of the position along the chain, as in statistical copolymers. These include gradient copolymers, which are defined as containing at least one section of continuously varying monomer composition. ${ }^{[1]}$

Gradient copolymers come in many guises: the literature contains references to linear gradients, ${ }^{[2,}$ 3] exponential gradients, ${ }^{[4]}$ hyperbolic gradients, ${ }^{[5]}$ stepwise gradients, ${ }^{[6]}$ spontaneous gradients, ${ }^{[7]}$ tapered blocks ${ }^{[8]}$ and quasi-blocks. ${ }^{[9]}$ But block copolymers with stepwise changes in monomer composition ${ }^{[10-12]}$ also fall into this category, and share many properties with gradient copolymers. As we will show in this review, the very concept of a 
continuously varying monomer composition is problematic when applied to chains that are composed of discrete monomer units.

The common feature that links all these structures is an asymmetric distribution of monomers within each chain. This feature is present both at the level of individual chains and in the average composition profile of the entire sample. Thus, in the context of this review we will refer to all polymers that display this characteristic as asymmetric copolymers (Figure 1). In this way, we avoid classifications that are based on either the method of synthesis (e.g. forced vs spontaneous gradient copolymers) or aggregate properties that are not expressed at the level of individual chains (e.g. linear and stepwise gradients).

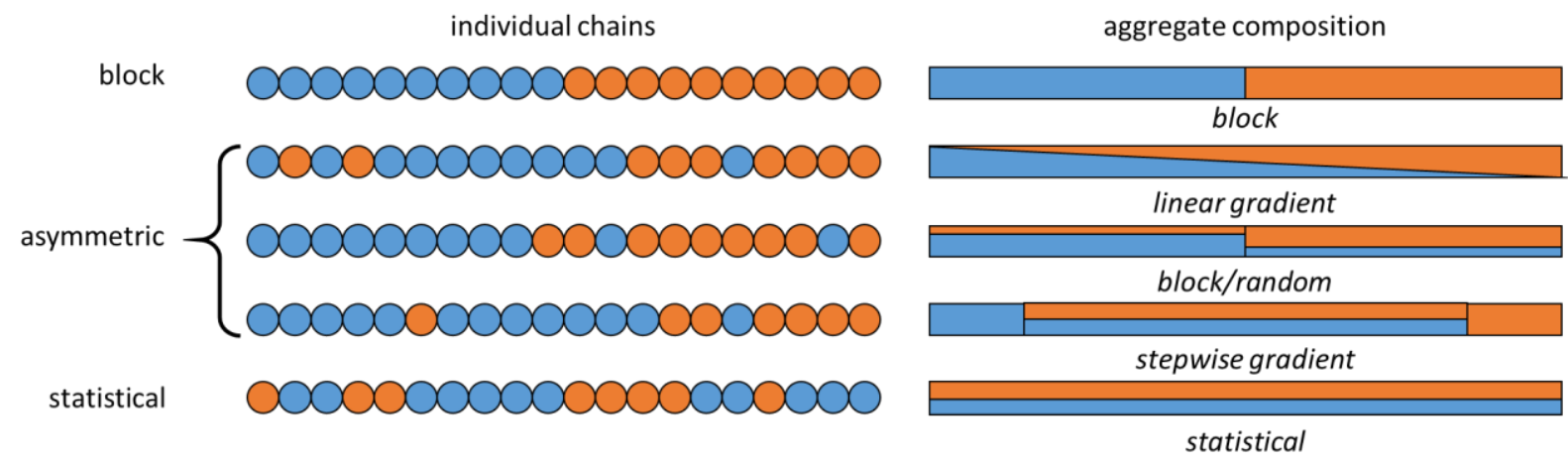

Figure 1. Asymmetric copolymers are defined by a distribution of monomers within the chain that is neither strictly segregated as in the case of block copolymers (top) nor uniformly mixed as in the case of statistical copolymers (bottom). This definition groups together many architectures with different aggregate composition profiles (right) but which are difficult to distinguish on the level of individual chains (left).

In this review, we first define what we mean by an asymmetric copolymer and briefly examine methods for their synthesis. Then we discuss the unique properties that result from an asymmetric monomer distribution. Finally, we highlight some examples of applications that make use of these properties. This review is not intended to be exhaustive, as several more narrowly focused reviews are available covering aspects of the synthesis and properties of different types of asymmetric copolymer. ${ }^{[1,13,14]}$ Instead we seek to provide an overview of the common properties that result from a degree of segregation between the monomers that is more 
pronounced than that of a statistical polymer, but which lacks the abrupt transition in composition of a block copolymer.

\section{What is an asymmetric copolymer?}

Gradient copolymers are defined as polymers that contain at least one segment of continually varying composition. ${ }^{[1]}$ Copolymers, however, are composed of discrete monomer units. Thus an A-stat-B copolymer contains units of A and units of B, but never a unit that is a mixture of A and B. At the level of individual chains, the composition alternates between $100 \% \mathrm{~A}$ and $100 \%$ B and cannot vary continuously.

This problem can be circumvented by defining the composition as the average composition of all polymers in the sample, or as a moving average of multiple units in a single chain. Both of these approaches present difficulties. Using the average composition of the entire sample leaves open the possibility of significant variation at the level of individual chains. This is illustrated by the case of a block copolymer composed of two segments of poly(A) and poly(B) of equal average length, each with a dispersity of 2 . All possible compositions $\left(0 \leq f_{\mathrm{A}} \leq 1\right)$ are represented in this polymer with equal probability. ${ }^{[15]}$ Hence the average composition as a function of chain length is perfectly linear, but the polymer is clearly a block copolymer (Figure 2).
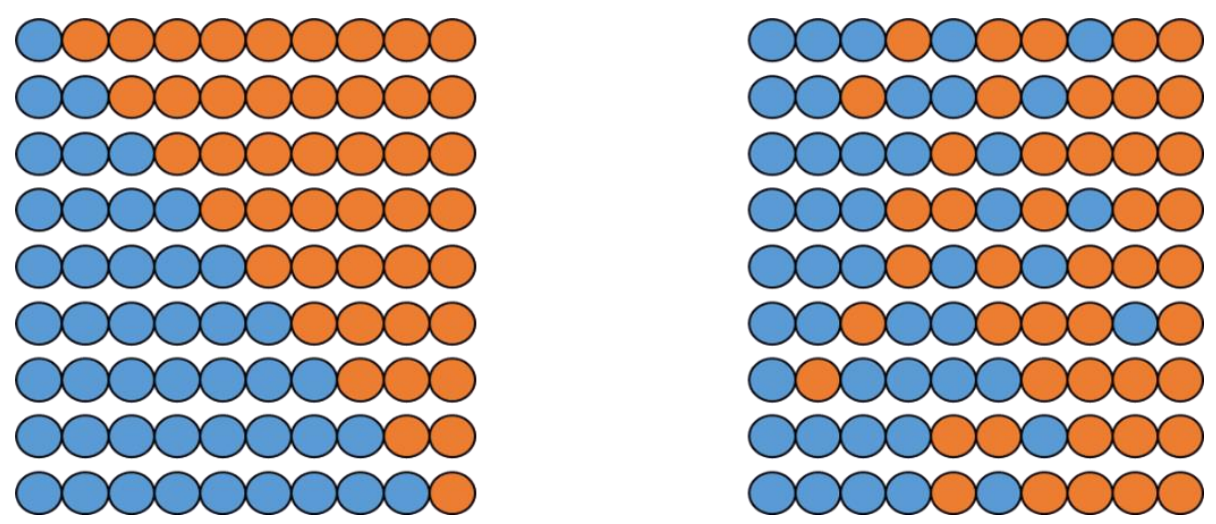

Figure 2. Samples of chains from a block copolymer with disperse blocks (left) and a gradient copolymer (right). Both copolymers have the same linear composition vs chain length profile. 
The moving average approach is equally limited in that long segments must be averaged in order to obtain fine distinctions in composition within a single chain. At least $n$ units must be averaged in order to distinguish changes in composition of the order of $1 / n$.

A common oversimplification is to equate the composition profile of each chain of a gradient copolymer to the aggregate composition gradient (the average of all chains, with conversion assumed to correspond to chain length). However, even perfectly controlled chain polymerizations exhibit variation in chain length, which leads to discrepancies between the assumed structure and the actual distribution of structures. ${ }^{[16]}$ This approach also ignores the discrete nature of each chain, the variation in composition between chains, the variation in chain length from one chain to another, and the imperfect correspondence between conversion and chain length (not all chains are initiated at the beginning of the reaction, nor do all chains survive to its end, and propagation occurs intermittently).

This problem also affects theoretical studies of gradient copolymers, which frequently rely on simplifying assumptions that are unlikely to be valid for the relatively short chains obtained in experimental systems. Examples of these assumptions are: that the composition of the polymer varies continuously; ${ }^{[17,18]}$ or that all chains are identical with respect to composition or length. ${ }^{[17-19]}$ A promising approach followed by Jiang et al. ${ }^{[2]}$ was to assume that the gradient copolymer can be represented by multiblock copolymer composed of segments of varying lengths. It is telling that 200 such segments were required in order to replicate the results obtained using an idealized continuously varying structure. Gradient polymers may also be approximated as multiblock copolymers containing polydisperse segments of different $\chi$, following the work of Dobrynin and Leibler. ${ }^{[20]}$ More recently, Ganesan et al. ${ }^{[21]}$ have examined chains which incorporate variation in sequence length and composition. This variation can have dramatic effects on the ability of gradient polymers to act as interfacial stabilizers and the phase-separated morphologies which are obtained. 
Several groups have attempted to improve the representation and classification of gradient copolymers. One approach is to display a number of simulated chains, with the probability of finding a monomer at each location determined by the monomer composition at the conversion corresponding to that location and the identity of the previous monomer added (Figure 3 ). ${ }^{[7,22-}$ ${ }^{24]}$ This provides information on the interchain variation as well as the distribution of alternating sequences and blocks within each chain, but still conflates conversion with chain length and is difficult to quantify numerically.

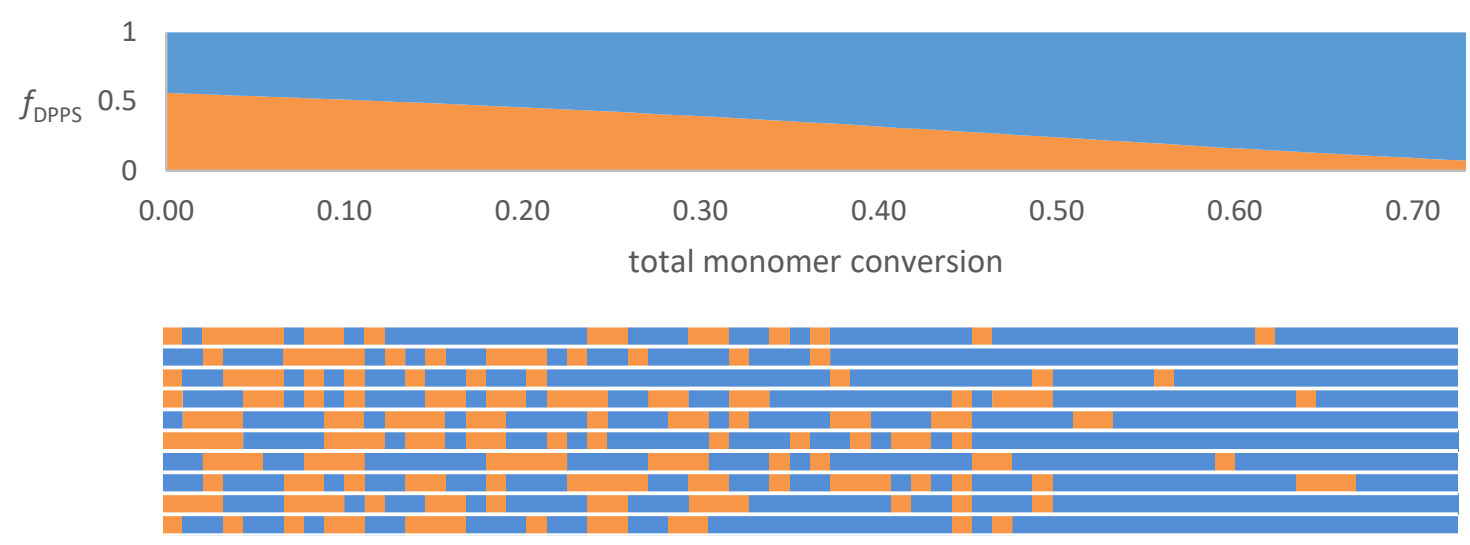

Figure 3. Depictions of gradient tendency in a styrene (S)-4-(diphenylphosphino)styrene (DPPS) copolymer containing 32 mol\% DPPS as average composition profile (top) or as a sample of simulated chains (bottom, coloured with DPPS in orange, $\mathrm{S}$ in blue). The lower representation shows the discrete nature of the polymer chains, typical block lengths, and the expected variation in composition between chains, but ignores the polymer length distribution and conflates conversion with chain length. Data from Sykes et al. ${ }^{[2]}$

Reyniers and coworkers ${ }^{[25]}$ have developed a numerical measure of the deviation from an ideal gradient, defined in terms of the number of monomers of a given type (A or B) found between one end of the chain and a given location within the chain $\left(\mathrm{S}_{\mathrm{A}}\right.$ or $\left.\mathrm{S}_{\mathrm{B}}\right)$, compared to the corresponding value $\left(\mathrm{S}_{\mathrm{A} \text {,ideal }}\right.$ or $\left.\mathrm{S}_{\mathrm{B} \text {,ideal }}\right)$ for an ideal gradient copolymer (equation 1$)$. This measure is rather complicated to calculate, must be evaluated four times (once for each monomer and in forward and reverse directions along the chain), and requires the specification of an ideal reference. 


$$
\begin{gathered}
\mathrm{GD}_{\text {BtoA }}(\mathrm{z})=\sum_{\mathrm{y}=1}^{\mathrm{i}} \frac{\left|\mathrm{S}_{\mathrm{A}}(\mathrm{y}, \mathrm{z})-\mathrm{S}_{\mathrm{A}, \text { ideal,BtoA }}(\mathrm{y}, \mathrm{z})\right|+\left|\mathrm{S}_{\mathrm{B}}(\mathrm{y}, \mathrm{z})-\mathrm{S}_{\mathrm{B}, \text { ideal,BtoA }}(\mathrm{y}, \mathrm{z})\right|}{\mathrm{i}^{2}} \\
\left\langle\mathrm{GD}^{*}\right\rangle=\sum_{\mathrm{z}=1}^{\mathrm{z}_{\max }} \frac{\mathrm{GD}(\mathrm{z})}{\mathrm{z}_{\max }}
\end{gathered}
$$

Finally, a method has been developed to experimentally determine gradient quality under the very specific circumstance where one of the monomers can be used as an initiator for a subsequent polymerization, leading to the formation of a bottlebrush. ${ }^{[26]}$ In this case, individual molecules can be visualized by AFM (Figure 4), and the density of functionalization evaluated as a function of chain length. Using this technique, Matyjaszewski and co-workers ${ }^{[26]}$ propose $^{2}$ the standard deviation of the instantaneous composition $\langle s\rangle$ as a measure of gradient quality (equation 2, where $h_{i}$ and $h_{a}$ represent the height of an individual chain and the average height of all chains, respectively, as measured by AFM).

$$
\langle s\rangle=\sqrt{\frac{1}{N} \sum_{\mathrm{i}=1}^{\mathrm{N}}\left\{\int_{0.1}^{0.9}\left[\mathrm{f}_{\mathrm{a}}(\mathrm{l}) \cdot\left(\frac{\mathrm{h}_{\mathrm{i}}^{2}(\mathrm{l})}{\mathrm{h}_{\mathrm{a}}^{2}(\mathrm{l})}-1\right)\right]^{2} \mathrm{dl} / \int_{0.1}^{0.9} \mathrm{dl}\right\}}
$$
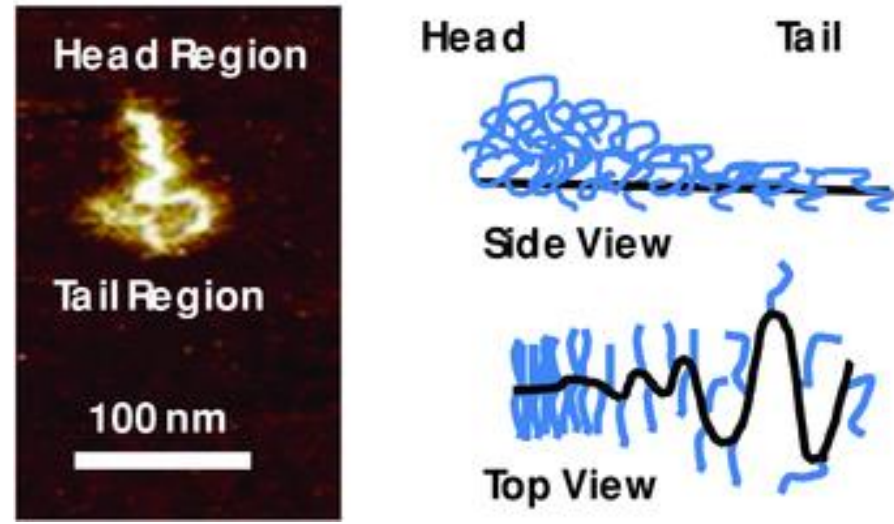

Figure 4. AFM height image with top and side-view representations of gradient molecular bottlebrushes on a surface. Reproduced from Elsen et al. ${ }^{[26]}$. (C) 2013 WILEY-VCH Verlag GmbH \& Co. KGaA, Weinheim The above techniques are complicated both conceptually and in implementation - hence there is still a strong need for a simple and experimentally accessible method for the classification and measurement of gradient quality. 
In the following discussion we have chosen to classify gradient-like copolymers on the basis of the distribution of monomers of different types on the level of individual chains. For a polymer to be classed as asymmetric it must satisfy two constraints (Table 1):

- The majority of chains should contain at least two segments of measurably different composition. While the exact structure of each chain will vary according to the statistical laws governing the copolymerization, most chains should have a similar composition vs length profile if evaluated at a sufficiently large scale.

- The chains should not have a well-defined transition from one compositional segment to another.

We class a copolymer as statistical if the different types of monomer are statistically distributed within each chain in a manner that is independent of the chain length, or as a block copolymer if there is a clear transition between the different types of monomer. Note that a conventional copolymerization that is subject to composition drift due to selective consumption of one monomer produces a blend of statistical copolymers of different compositions rather than an asymmetric copolymer: while the average copolymer composition varies as the polymerization proceeds, within each individual chain the arrangement of monomers is described by statistical laws that are independent of the position within the chain.

Table 1. Distinguishing statistical, block and asymmetric copolymers.

\begin{tabular}{|c|c|c|c|}
\hline Structural Property & Statistical & Block & Asymmetric \\
\hline $\begin{array}{c}\text { Segments of measurably different composition } \\
\text { which are reproduced in nearly all chains }\end{array}$ & No & Yes & Yes \\
\hline $\begin{array}{c}\text { Well-defined transition from one segment to } \\
\text { another }\end{array}$ & No & Yes & No \\
\hline
\end{tabular}

\section{Synthesis of asymmetric copolymers}


There are many options for the preparation of asymmetric copolymers, ranging in complexity from the one-pot synthesis of spontaneous gradient copolymers to semibatch processes for the preparation of forced gradient copolymers with continuously varying monomer feed profiles. In general, more complex synthetic methods give, at least in principle, greater control over the final copolymer profile, but at the price of more side reactions such as termination, which lead to deviations from the desired composition profile. The major synthetic approaches are summarized in Figure 5.

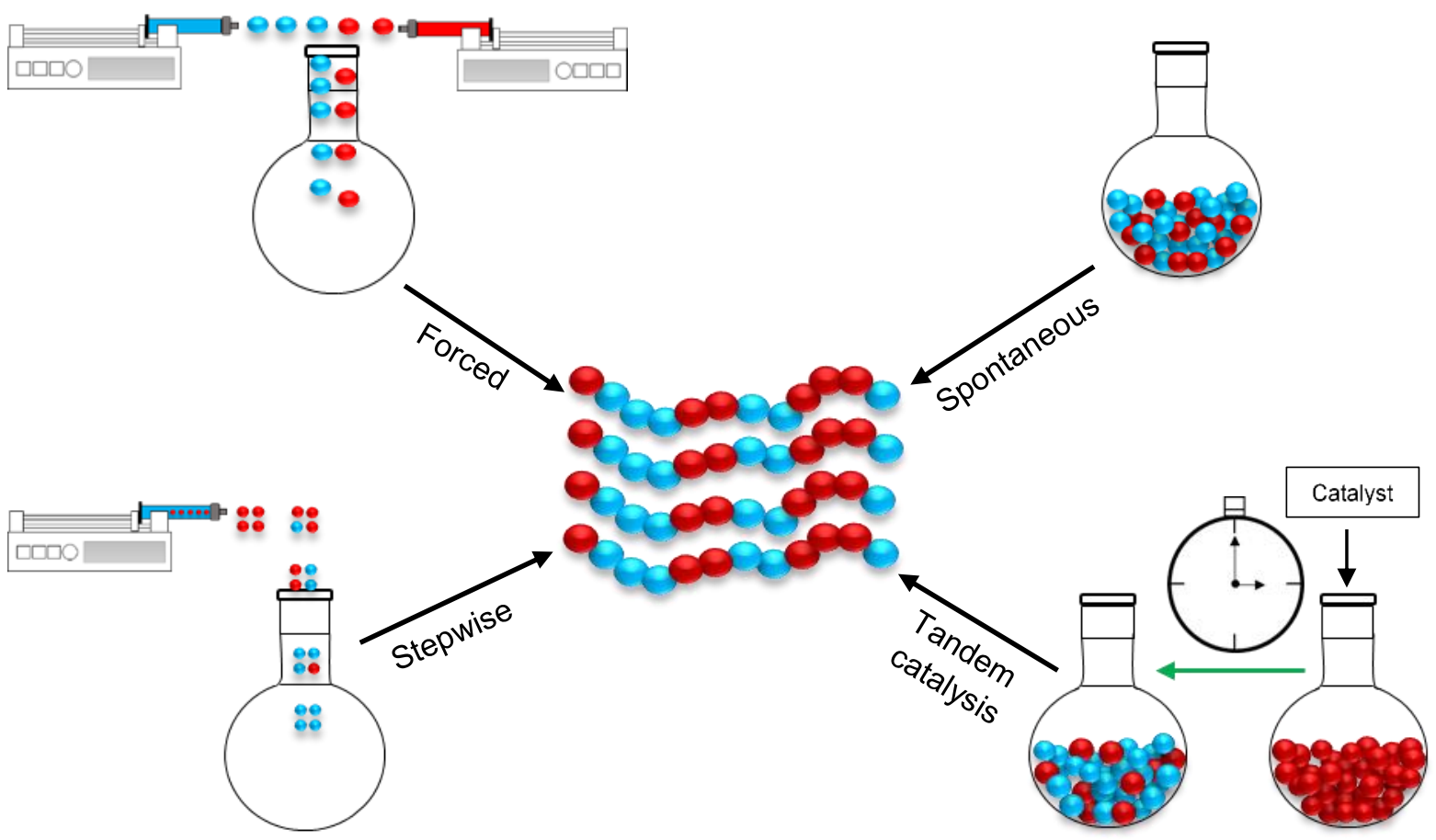

Figure 5. Major synthetic approaches to the preparation of asymmetric copolymers.

All techniques for preparation of asymmetric copolymers combine the use of living or controlled (e.g., RDRP) polymerization techniques, in which the majority of chains are at least periodically active during the majority of the polymerization, with a steadily varying monomer composition in the reaction medium. This enables each chain to sample the changing composition of the reaction medium throughout the reaction, ensuring that all chains have a similar composition profile. Asymmetric copolymers cannot be prepared using conventional radical polymerization techniques, as in these techniques the lifetime of each chain is extremely 
short compared to the overall reaction time. Thus any changes in the composition of the reaction mixture that occur during polymerization are not reflected in the composition profile of individual chains, and instead manifest as differences in composition between polymer chains.

Many techniques have been used for the preparation of asymmetric copolymers, including anionic $^{[27]}$ and cationic $^{[28-33]}$ polymerizations, C1 polymerization, ${ }^{[34]}$ catalyst transfer polycondensation, ${ }^{[35]}$ catalyzed copolymerization of olefins ${ }^{[36]}$ and epoxides, ${ }^{[37]}$ ROMP $^{[38-42]}$ and various RDRP techniques (e.g. ATRP, ${ }^{[43-48]} \mathrm{NMP},{ }^{[49-56]}$ OMRP, ${ }^{[57]}$ and RAFT,${ }^{[22-24,58-61]}$ ). Similarly, a wide range of monomers have been used, including acrylates and methacrylates, ${ }^{[26,}$ ${ }^{43,45]}$ acrylamides/methacrylamides, ${ }^{[22,23]}$ styrenics, ${ }^{[24,27,62]}$ olefins, ${ }^{[36,62]}$ vinyl esters ${ }^{[22,23]}$ and epoxides. ${ }^{[37]}$ Both monomers must be compatible with the chosen polymerization technique and should ideally propagate rapidly and terminate relatively slowly in order to allow long chains to be prepared while maintaining acceptable levels of termination. Thus in radical polymerizations acrylates and acrylamides are frequently used, as they offer a wide range of functionalities, high rate constants of propagation and acceptable levels of termination.

The following sections describe some of the major techniques for the preparation of asymmetric copolymers.

\subsection{Spontaneous method}

When two monomers are copolymerized, the composition of the resulting polymer is generally different from that of the monomer mixture. In most cases, this composition is well described by a simplified kinetic scheme which assumes that all propagating chains with the same terminal unit are kinetically equivalent. This model gives rise to the Mayo-Lewis equation (eq. $\left.3^{[63]}\right)$, which describes the instantaneous copolymer composition $\left(F_{\mathrm{A}}, F_{\mathrm{B}}\right)$ in terms of the monomer mole fractions $\left(f_{\mathrm{A}}, f_{\mathrm{B}}\right)$ and two reactivity ratios $\left(r_{\mathrm{A}}, r_{\mathrm{B}}\right)$.

$$
F_{A}=\frac{r_{A} f_{A}^{2}+f_{A} f_{B}}{r_{A} f_{A}^{2}+2 f_{A} f_{B}+r_{B} f_{B}^{2}}
$$


If one comonomer is incorporated at a higher concentration in the polymer than in the monomer feed, the reaction mixture will become depleted in that monomer as the polymerization proceeds. This in turn causes a change in the copolymer composition, which is described by the integrated form of eq. 3 (also known as the Skeist equation, eq. $4^{[64]}$ ):

$$
\begin{array}{rr}
X=1-\left(\frac{f_{1}}{f_{1,0}}\right)^{\alpha}\left(\frac{f_{2}}{f_{2,0}}\right)^{\beta}\left(\frac{f_{1,0}-f_{a z}}{f_{1}-f_{a z}}\right)^{\gamma} & \\
\alpha=\frac{r_{2}}{1-r_{2}} & \gamma=\frac{1-r_{1} r_{2}}{\left(1-r_{1}\right)\left(1-r_{2}\right)} \\
\beta=\frac{r_{1}}{1-r_{1}} & f_{a z}=\frac{1-r_{2}}{2-r_{1}-r_{2}}
\end{array}
$$

Some examples of copolymer composition trajectories are shown in Figure 6 for different reactivity ratios. In a living or controlled polymerization, this drift in composition will be reflected in each polymer chain. The fidelity with which the overall change in composition is reflected in a single chain will depend on both the length of the chain (longer chains can exhibit smaller changes in composition) and the frequency of activation/deactivation cycles (chains that are activated more frequently sample the polymerization more often). 

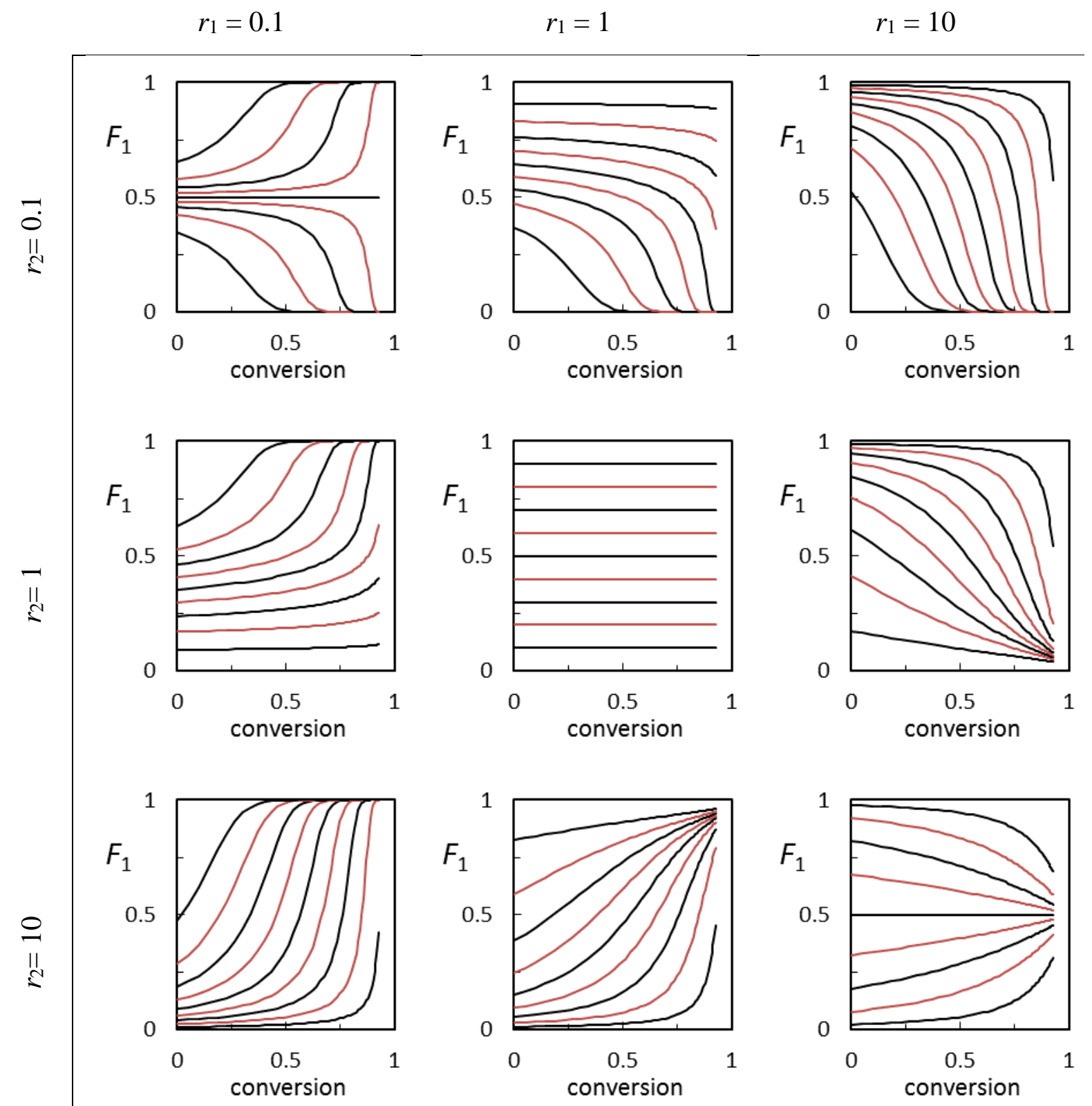

Figure 6. Copolymer composition trajectories for various $r_{1}$ and $r_{2} . F_{1}$ represents the instantaneous mole fraction of $M_{1}$ in the copolymer. Initial fraction of $M_{1}$ ranges from 0.1 to 0.9 in steps of 0.1 .

It can be seen that in many cases relatively little drift in composition takes place until high conversions are reached. If the polymerization is stopped before full conversion (for example in order to limit loss of chain end functionality) the desired gradient may not be realized.

If both reactivity ratios are less than one, or if both reactivity ratios are greater than one, there is an azeotropic composition, $f_{\mathrm{az}}$, at which the composition of the polymer is equal to that of the monomer. In this case, it is not possible to cover the full range of compositions with a single 
gradient copolymer - if the copolymer composition is richer in a given monomer than the azeotropic composition at any point in the reaction, it will remain so for the entire reaction. Spontaneous gradient copolymers have been obtained via catalyst transfer polycondensation, ${ }^{[35]}$ catalyzed copolymerization of olefins ${ }^{[36]}$ and epoxides, ${ }^{[37]}$ diverse RDRP methods (ATRP, ${ }^{[43-48]} \mathrm{NMP},{ }^{[49-56]}$ OMRP $,{ }^{[57]} \mathrm{RAFT},{ }^{[22-24,58-61]}$ ) as well as cationic ring opening polymerization. ${ }^{[28-33]}$ Also, the gradient-composition backbone can be used as macroinitiators to synthesize high molecular weight brushes. ${ }^{[65]}$ However, this kind of approach will sometimes lead to "block-like" structure. ${ }^{[7]}$

The advantages of this technique are that it is simple to implement and easy to reproduce, as the copolymer composition profile is fully determined by the initial feed composition. This is compensated by a corresponding lack of flexibility - only one composition profile can be attained for a given monomer pair at a given composition. The technique tends to produce either shallow gradients with relatively small overall change in composition ${ }^{[24,66]}$ or block-like structures with initial region of nearly constant composition, a relatively steep transitional region, and a final segment of homopolymer. ${ }^{[7,22,23]} \mathrm{A}$ common problem is that the reaction stops when the more reactive monomer has been consumed ${ }^{[67]}-$ the resulting copolymer has near constant composition even though the monomer composition changes significantly during the reaction. In addition, it can be difficult to control the copolymerization of two monomers of very different reactivity (e.g. methyl acrylate and vinyl acetate). For this purpose, xanthatemediated RAFT polymerization is particularly useful as xanthates provide good control over less activated monomers such as vinyl esters ${ }^{[68]}$ and vinylamides (and lactams), coupled with acceptable levels of control over more activated monomers such as acrylates ${ }^{[69]}$ and acrylamides $^{[70]}$. Numerous examples of xanthate-mediated spontaneous gradient copolymers can be found in the literature. ${ }^{[22,23,58,71,72]}$

\subsection{Stepwise method}


A conceptually simple method to produce polymers with an asymmetric composition profile is to carry out sequential copolymerizations at different monomer compositions. In this way, a stepwise composition profile comprising multiple blocks of different composition can be obtained. By increasing the number of blocks, a continuous composition profile can be approached as closely as desired. Stepwise gradient and related asymmetric copolymers have been prepared by different methods including NMP, ${ }^{[50,73-77]}$ ATRP, ${ }^{[78]}$ RAFT, ${ }^{[60,79,80]}$ as well as by living anionic polymerization ${ }^{[27,81]}$ and $\mathrm{C} 1$ copolymerization, a polyhomologation reaction that uses methylene and ethylidene ylide monomers as substrates. ${ }^{[34]}$

An example of the stepwise approach is the preparation of styrene-n-butyl acrylate copolymers using a 'many shot' RAFT emulsion polymerization (Figure 7$)^{[80]}$. Linear and V-shaped stepwise gradients were prepared using this method.
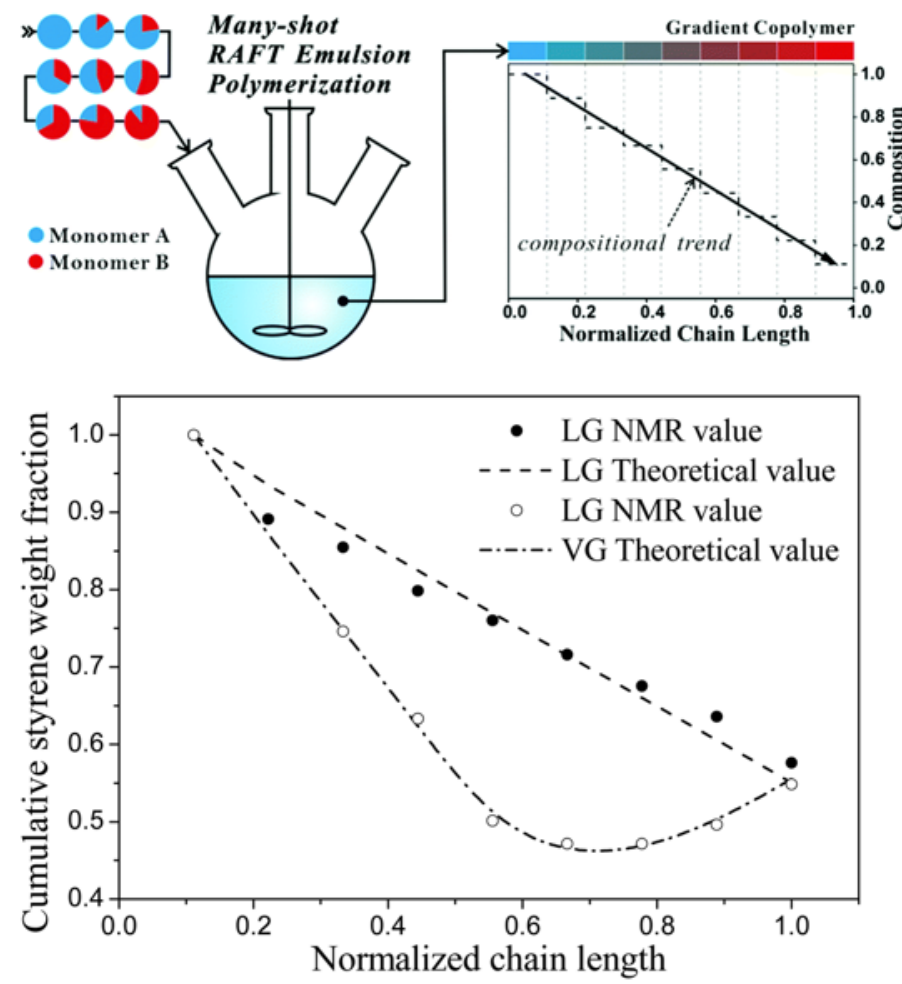

Figure 7. Many shot emulsion polymerization method for preparation of linear and V-shaped gradient copolymers. Reproduced from Guo et $a l^{[80]}$ with permission of the Royal Society of Chemistry. http://dx.doi.org/10.1039/C4PY00003J

One-pot syntheses of multiblock copolymers are well-developed and have been reported for many polymerization techniques, including single-electron transfer LRP (SET-LRP), ${ }^{[82-85]}$ 
photoinduced LRP, ${ }^{[86,87]}$ and RAFT,${ }^{[88-91]}$ However, the occurrence of side reactions, especially in radical polymerizations, will inevitably lead to a loss of livingness as the number of blocks and reaction time increase. ${ }^{[92]}$ Furthermore, it is not currently known how many blocks are required to achieve gradient-like properties. In several cases, though, as few as two blocks are sufficient to achieve properties typically associated with gradient copolymers such as dynamic exchange between micelles. ${ }^{[10,11,93,94]}$

\subsection{Forced method}

While the spontaneous gradient approach is simple, the composition profiles that can be obtained are limited by the reactivity ratios of the monomers. ${ }^{[39,95,96]}$ Stepwise methods, in turn, are unable to produce continuously changing composition profiles. Forced gradient copolymerization, in which one or both monomers are added continuously during the

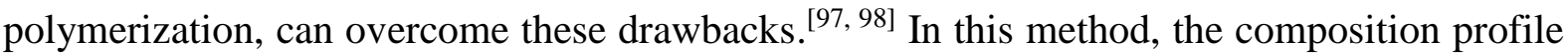
of the polymer is determined by controlling the feeding rate of the monomers. ${ }^{[3,97,99-103]}$ This technique is simplest to apply to monomers of similar reactivity (i.e. reactivity ratios close to 1), ${ }^{[104]}$ but can also be applied to monomer pairs with very different relative reactivity. ${ }^{[105]}$ Compared to the spontaneous process, a wider range of monomer pairs are suitable for this method, and a much wider range of composition profiles is achievable. However, drawbacks include not only complex experimental set up, low repeatability and reproducibility, but also lower polymerization rate, broader molar mass distribution, and higher fraction of dead chains compared to batch copolymerization. ${ }^{[3]}$

Forced gradient copolymers prepared by different reaction mechanisms, such as NMP, ${ }^{[73,74,}$ ${ }^{106-115]} \mathrm{Ni}$-catalyzed chain-growth polycondensation, ${ }^{[116-119]}$ ATRP, ${ }^{[120,121]} \mathrm{RAFT}^{[122-124]}$ and living cationic polymerization ${ }^{[125-128]}$ have been extensively described in the literature. Routinely, a syringe pump is used during the synthesis to control the monomer feed and tailor the gradient profile of the materials (Figure 8). Programmed comonomer feeding makes it 
possible to precisely design and control the composition distributions along the polymer chain. ${ }^{[100,103,129,130]}$ Broadelt and Wang reported that a variable feed profile was required to make 'structural gradient' copolymers, in which the average segment length varies along the chain. ${ }^{[103]}$

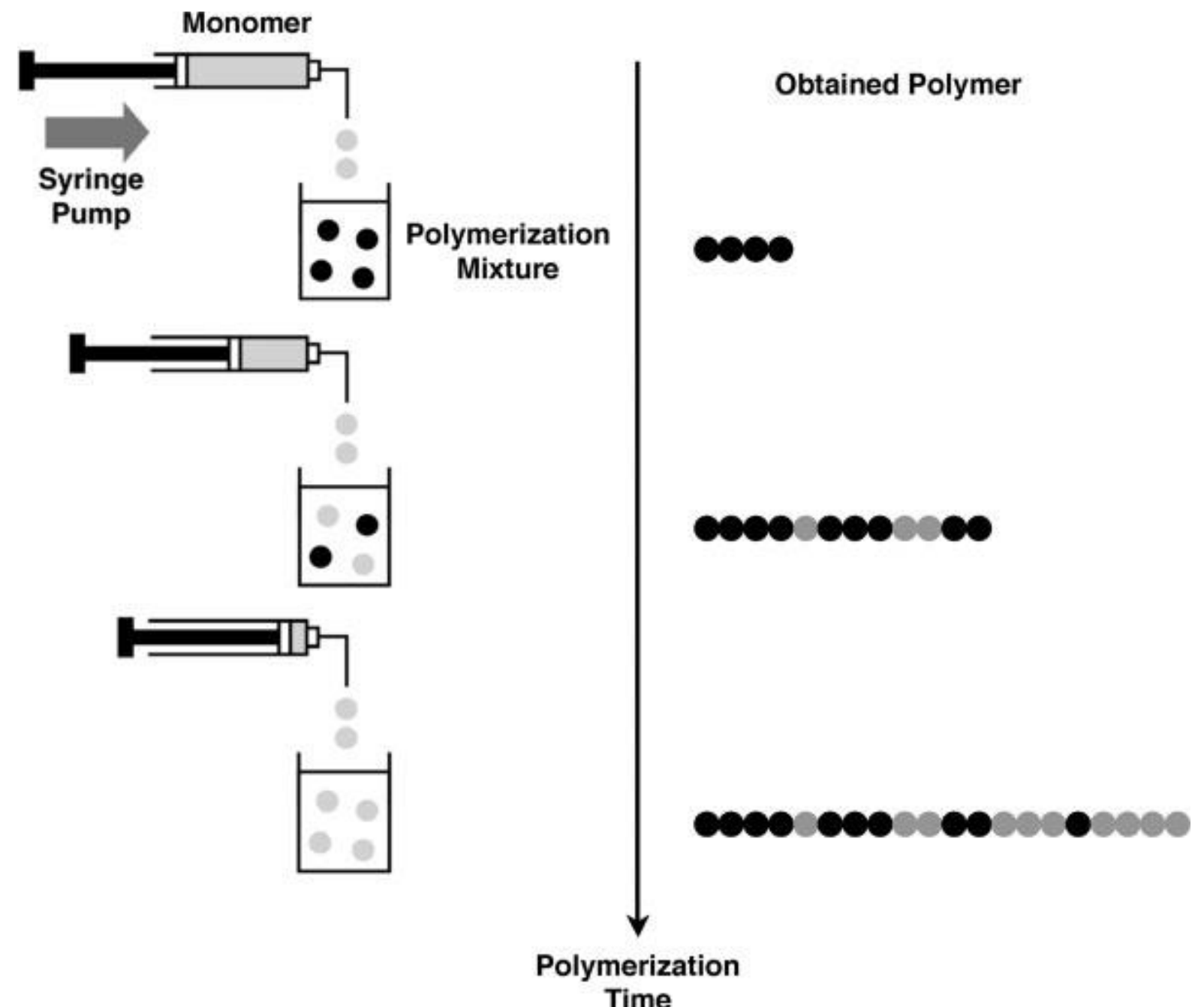

Figure 8. Schematic illustration of synthetic approach for gradient copolymers using a forced method. Reproduced from Seno et al. ${ }^{[128]}$. ( 2008 Wiley Periodicals, Inc.

Operationally, the simplest way to produce an asymmetric copolymer with any desired composition profile is to add both monomers simultaneously under starved-feed conditions. ${ }^{[131]}$ In this case, the monomer concentration in the reactor is very low throughout the polymerization, and the copolymer composition will always closely approximate the monomer feed. However, as propagation is limited by the low monomer concentration, higher incidence of side reactions is expected compared to batch polymerization. As a result, starved-feed 
conditions are best suited to emulsion polymerizations where the effects of side reactions such as termination are greatly reduced compared to bulk polymerizations. ${ }^{[97]}$

Applying continuous flow reactors for the synthesis of polymers can reduce side reactions such as branching ${ }^{[132]}$ and allows for rapid production of polymer libraries by simply varying the process conditions. ${ }^{[133]}$ However, their use in the synthesis of forced gradient copolymers has been restricted by the need to continuously vary the monomer feed. This problem has recently been overcome by the use of a tube-in-tube continuous flow reactor which allows a wide variety of gradient copolymers to be synthesized by varying the flow rates and monomer ratios through the reactor (Figure 9). ${ }^{[124]}$

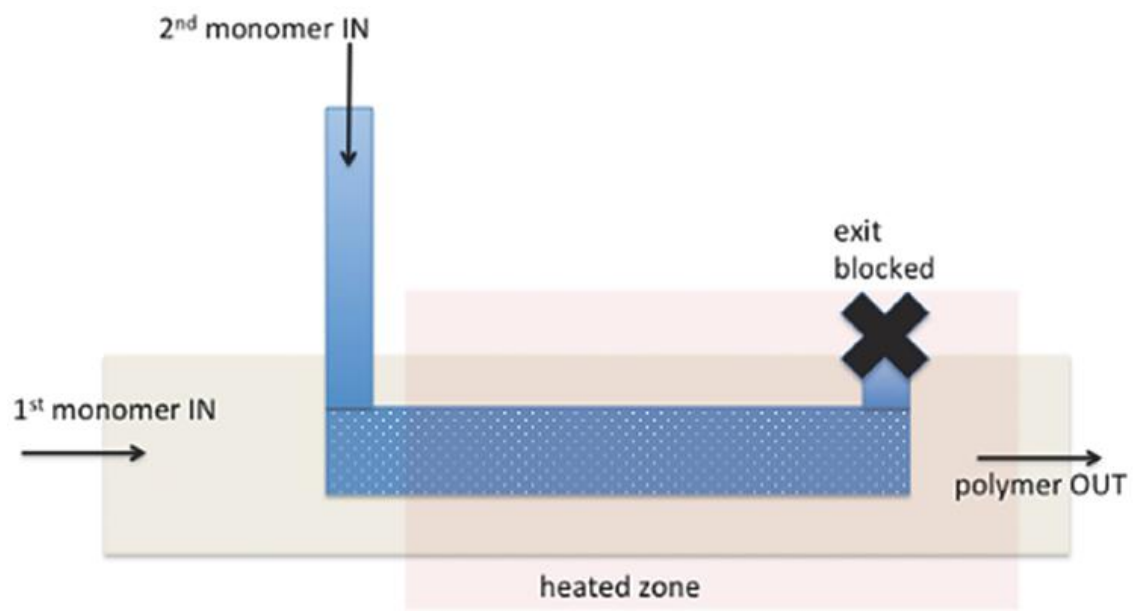

Figure 9. Diagram showing "forward" flow in the reactor with the two reagent streams mixing before the heated zone. Reproduced from Saubern S. et al. ${ }^{[124]}$ @) 2017 WILEY-VCH Verlag GmbH \& Co. KGaA, Weinheim.

\subsection{Concurrent polymerization and monomer transformation}

Terishima, Sawamoto and co-workers ${ }^{[134]}$ have developed a new one-pot synthetic method for preparing functional copolymers from monomers of similar reactivity. This method is based upon the concurrent tandem catalysis of Ru-catalysed RDRP of (meth)acrylates and their in situ metal alkoxide catalysed transesterification. Synchronisation of the rates of RDRP and transesterification allows direct access to linear gradient copolymers (Figure 10). ${ }^{[134,135]}$ Other architectures such as random, block, gradient-block and bidirectional gradient copolymers are also accessible via tailoring parameters such as the relative rates of tandem catalysis, the timing 
of reagent introduction (e.g. sequential vs concurrent addition of catalysts and/or monomer(s)) and the functionality of the initiating species. ${ }^{[135,136]}$

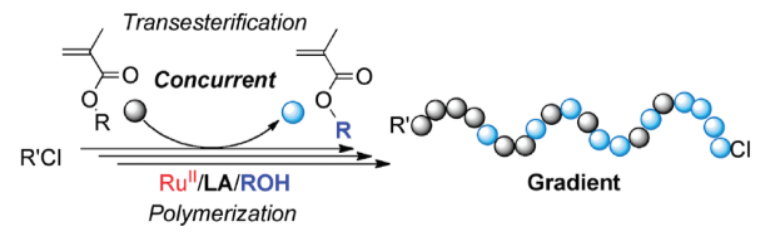

Figure 10. Concurrent tandem catalysis of Ru-catalysed RDRP and metal alkoxide-catalyzed transesterification. Adapted with permission from Nakatani et al. ${ }^{[135]}$ Copyright $@ 2012$ American Chemical Society.

A critical point for the success of gradient copolymer synthesis via the tandem catalysis method is a high level of selectivity in transesterification between the monomeric and polymeric esters; ideally the pendent esters on the polymer should be inert. ${ }^{[134,135,137]}$

This constraint is met for methacrylate (co)polymerization, however the technique is less reliable for the synthesis of acrylate-based gradients, ${ }^{[134,135]}$ due to the decreased steric bulk around the polymeric ester moieties and hence increased rate of transesterification. For methacrylates the technique appears general with primary alcohols bearing a range of functionalities, with aliphatic alcohols, $\left.{ }^{[134,}{ }^{135}\right]$ poly(ethylene glycol), ${ }^{[135,}{ }^{136]}$ fluorinated alcohols, ${ }^{[138,139]}$ and alcohols bearing hydrogen-bond motifs ${ }^{[140]}$ being exploited to date.

More recently, Tao and co-workers used a related technique based on concurrent RAFT polymerization and enzymatic transesterification of methacrylates and alcohols. ${ }^{[141]}$ The use of an enzymatic transformation provides a means towards chiral gradients; the preferential incorporation of one enantiomer of racemic 2-octanol offers preliminary results in this context. $^{[141]}$

Very recently, Zhang and co-workers reported the preparation of simultaneous, hierarchical, di-block, symmetrical, and tri-block gradient copolymers by copolymerizing methyl methacrylate (MMA) and furan-protected propyl maleimide (FPMI) via RAFT polymerization. ${ }^{[142]}$ In contrast to studies of Sawamoto et al. and Tao et al., no catalyst was 
used. During the polymerization at $100{ }^{\circ} \mathrm{C}$, propyl maleimide was generated in situ from FPMI via a retro-Diels-Alder (rDA) reaction to undergo copolymerization with MMA.

Arriola and co-workers ${ }^{[143]}$ reported the synthesis of ethylene-based asymmetric copolymers via "chain shuttling polymerization" in which a dual-catalyst/chain shuttling agent (CSA) system was used. This system applies a chain shuttling agent to facilitate growing chains transfer between two distinct catalysts with different monomer selectivities in a continuous polymerization reactor. Two catalysts (Cat 1 and Cat 2) were used to copolymerize ethylene and octane. Cat 1, with high ethylene selectivity, was applied to produce a segment of hard polymer with low comonomer content. Meanwhile, Cat 2, a good incorporator of comonomer octane, generates a soft copolymer of higher comonomer content. Shuttling occurs between polymer chains bearing an effective CSA. Further chain growth then extends a soft copolymer chain with a hard segment (and vice versa) to give an asymmetric copolymer. The overall composition, e.g. the soft-to-hard segment ratio, can be easily controlled by the relative amount of the catalysts used. This strategy can be used to generate olefin-based copolymers maintaining excellent elastomeric properties for high temperature applications

\section{Properties of asymmetric copolymers}

In many cases, the properties of asymmetric copolymers are intermediate between those of block and statistical copolymers of the same composition and molar mass, as might be expected from their composition profiles, which combine aspects of both structures. ${ }^{[42]}$ Thus the broad glass transition temperatures that are frequently cited as a characteristic of gradient copolymers are also exhibited by weakly segregating A-B block copolymers, provided the $\chi N$ (where $\chi$ is the Flory-Huggins parameter describing excluded volume interactions between A and B blocks, $N$ is the degree of polymerization of the polymer chain) values are fairly close to the critical value- $(\chi N)_{\mathrm{c}}$ of A-B block copolymers. ${ }^{[2]}$ The dynamic response of amphiphilic gradient copolymer micelles to environmental conditions can also be explained by the reduced 
interfacial tension between the hydrophobic segment and the solvent as a result of the incomplete segregation of hydrophilic and hydrophobic units. ${ }^{[6,144-146]}$ But asymmetric copolymers may also show properties that are not found in block or statistical copolymers, notably the 'reel-in' effect observed as micelles of gradient copolymers adjust to changing solvent conditions. Some of the key properties exhibited by asymmetric copolymers are shown in Figure 11.

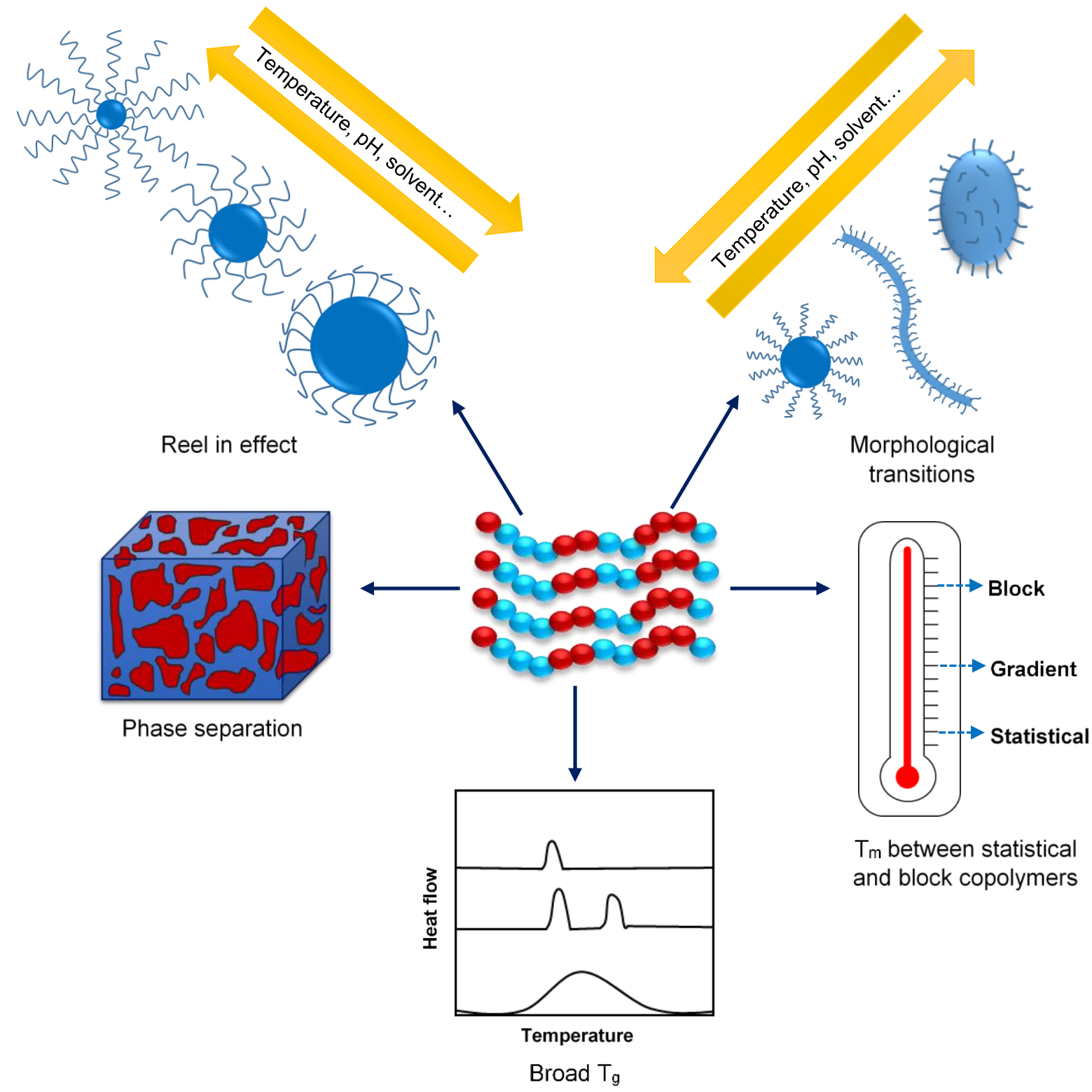

Figure 11. Some key properties of asymmetric copolymers in bulk and solution

3.1 Self-assembly in a selective solvent 
Micellization of gradient copolymers is a continuous and reversible process, whereas a stepwise transition is observed for block copolymers. ${ }^{[56]}$ The association process of the block copolymers is effectively irreversible, which results in non-equilibrium kinetically "frozen" micelles, which cannot be re-arranged in response to the variation of the environmental conditions. ${ }^{[93,147]}$ This is because the hydrophobic block needs to overcome a very high activation energy in order to escape from the core: $E_{\mathrm{a}} \propto \mathrm{N}^{2 / 3} \gamma$, where $\mathrm{N}$ is its degree of polymerization and $\gamma$ is the interfacial tension between the hydrophobic block and the solvent. ${ }^{[93,148]}$ It has been demonstrated that only when the blocks are very short ${ }^{[149]}$ or $\gamma^{[150]}$ is small will the association of block copolymers become dynamic.

In this respect, the preparation of asymmetric copolymers that incorporate hydrophilic units into the hydrophobic block is an efficient way to decrease $\gamma \cdot{ }^{[10,11,53,144,151]}$ Colombani and coworkers have performed a detailed investigation of the self-assembly of amphiphilic copolyelectrolytes consisting of a central poly(acrylic acid) (PAA) block and terminal poly $(n$ butyl acrylate- $c o$-acrylic acid) blocks containing different fractions of AA units. These systems form dynamic associations over a wide range of degrees of ionization, allowing fine-tuning the $\mathrm{pH}$ range over which the system transforms from a low viscosity liquid to a self-supporting hydrogel (Figure 12). By contrast, fully segregated triblock systems formed kinetically frozen associations. ${ }^{[6,145,146,152-156]}$ 


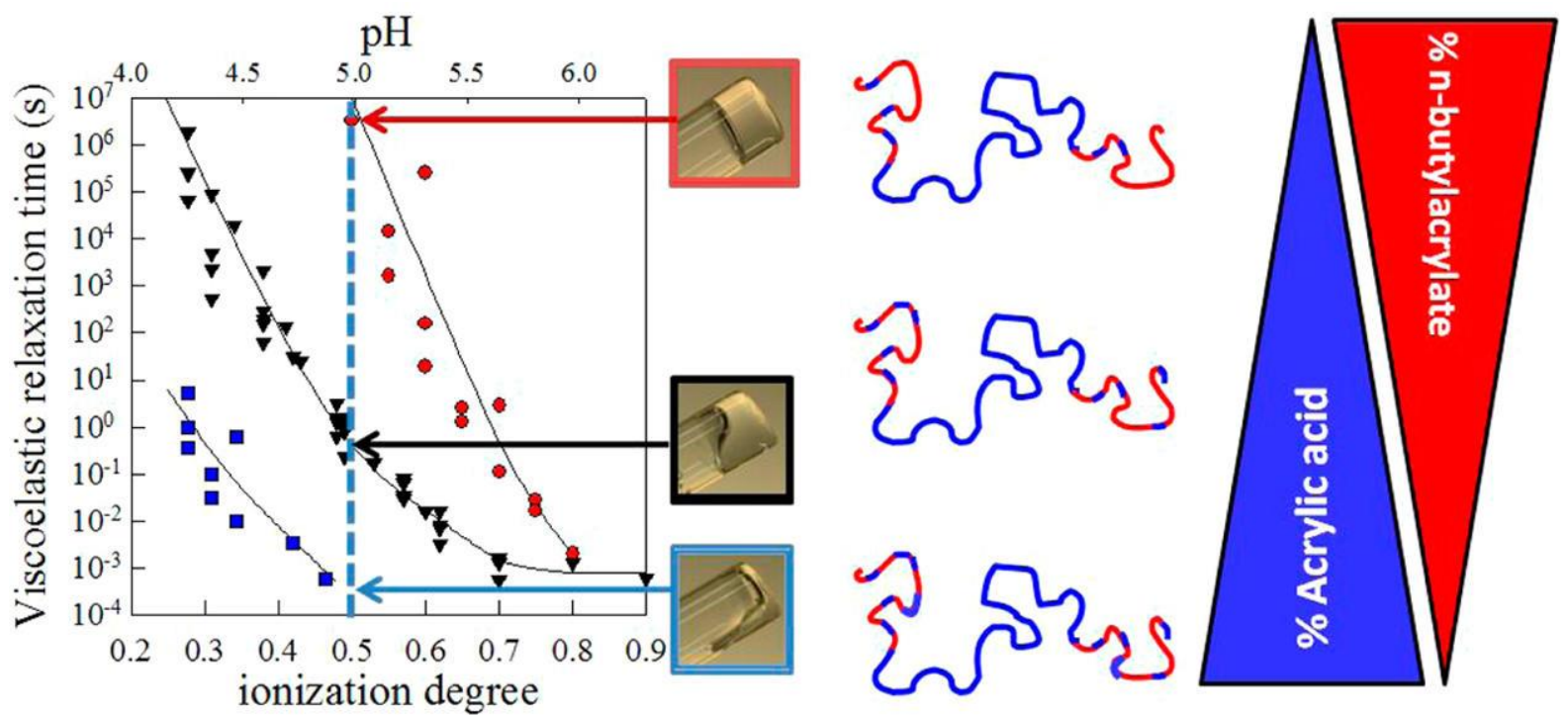

Figure 12. Dependence of the relaxation time on the degree of ionization for amphiphilic copolyelectrolytes consisting of a central poly(acrylic acid) (PAA) block and terminal poly(n-butyl acrylate-co-acrylic acid) blocks containing 40 (red), 50 (black) or 60 (blue) mol\% of AA units. Adapted with permission from: Shedge et al. ${ }^{[152]}$. Copyright (C) 2014 American Chemical Society

As for block copolymers, the self-assembly of asymmetric copolymers may be induced by changing the solvent quality such that one component becomes insoluble. This may be

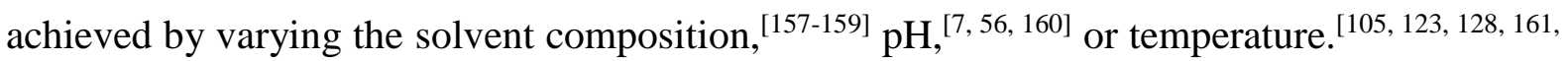
${ }^{162]}$ Where block copolymers undergo sharp transitions between dissolved and aggregated species, asymmetric copolymers undergo continuous evolution with changing solvent conditions, as polymer segments of different compositions react differently. In pH-responsive asymmetric copolymers, the sharper the gradient profile, the lower the $\mathrm{pH}$ required to trigger the conformational change and the narrower the $\mathrm{pH}$ range needed to complete the transition. ${ }^{[160]}$ The critical temperature for temperature-induced micellar structural transitions is subject to both the solvent and copolymer composition. ${ }^{[163,164]}$ In general, micellar sizes are smaller for self-assembled gradients than for analogous block copolymer systems, both in water ${ }^{[125]}$ and in $\mathrm{ScCO}_{2} \cdot{ }^{[165]}$

The reel-in effect. The continuous transformation with changing solvent quality observed for the gradient copolymers has been explained by a "reel-in" effect operating during the 
micellization process (i.e., the winding of polymer chains to the core of a micelle because of the gradient composition akin to reeling in a fishing line). ${ }^{[125]}$ Due to the compositional variation of gradient copolymers along the polymer chain, the solubility also changes gradually from one end of the molecule to the other.

Seno et al. demonstrated this effect with a series of poly(vinyl ether)-based thermo-responsive gradient copolymers which form micelles in water. ${ }^{[105,128]}$ These micelles decrease in size with increasing solution temperature, due to LCST behavior of the coronal segment. Under the same conditions micelles of either analogous block or random copolymers remained constant in size (see Figure 13). ${ }^{[105]}$ This continuous, "reel in" phenomenon was also observed with small-angle neutron scattering; gradual microphase separation took place in semi-dilute aqueous solutions of gradient copolymers as the temperature increased. In contrast, a stepwise transition was observed for the analogous block copolymer systems. ${ }^{[126,127]}$

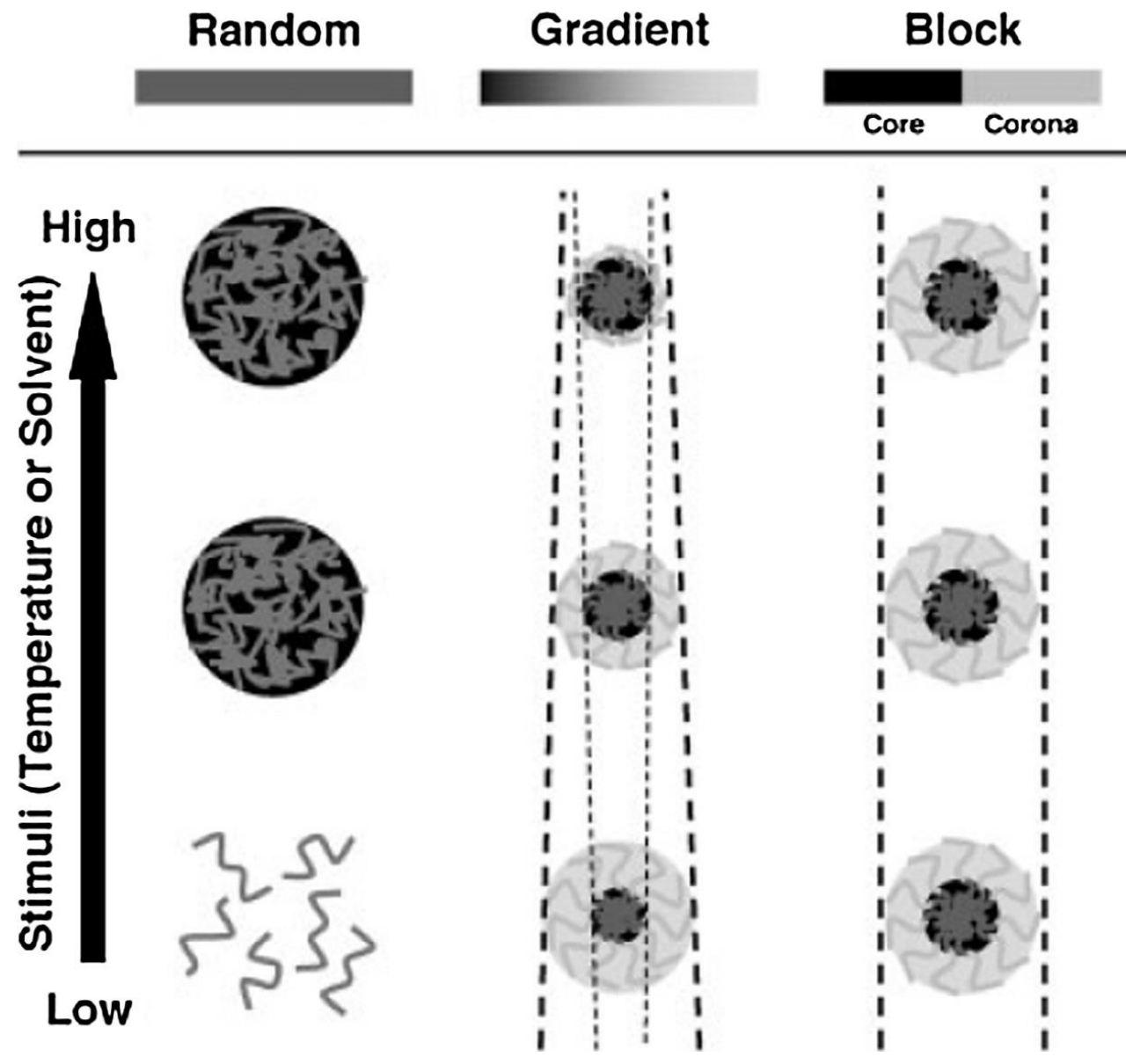


Figure 13. Schematic illustrations of micellization behavior in solution of stimuli-responsive gradient, block, random copolymers. Adapted from Seno et al. ${ }^{[105]}$ @ 2008 Wiley Periodicals, Inc

Similar behavior has been observed for gradient copolymers of lauryl methacrylate and styrene in a selective solvent for lauryl methacrylate: when the solvent quality is increased, the micellar cores shrink and the coronas increase due to the gradual solubilization of the domains where the two monomeric segments are mixed. ${ }^{[166]}$ In contrast, micelles of asymmetric copolymers of acrylic acid and styrene became larger and the number of micelles decreased as the $\mathrm{pH}$ was reduced and the acrylic acid-rich segments became less soluble, ${ }^{[56]}$ indicating agglomeration of micelles rather than a 'reel-in' effect in this case.

Similarly to block copolymers, amphiphilic gradient copolymers form a range of different nano-structures through self-assembly in solution, the morphology of which is greatly influenced by their composition. ${ }^{[23,30,167]}$ In contrast to the abrupt change in composition of block copolymers, no discrete point exists within individual asymmetric copolymer chains separating them into two distinctly different constituent parts. Therefore, in contrast to micelles of amphiphilic block copolymers which display a distinct core-shell structure, the solvophilic and solvophobic monomer units are less segregated within asymmetric copolymer micelles. ${ }^{[4]}$ In aqueous solutions of $\mathrm{pH}$-responsive copolymers, Zhu and co-workers found that all of the hydrophobic units of diblock and triblock copolymers reside in the micellar core, whereas some hydrophobic units of gradient copolymers were found in the hydrophilic shells. ${ }^{[160]}$

He and co-workers observed three types of structural transition in solutions of temperatureresponsive poly(styrene-co-methyl methacrylate) gradient copolymers: unimers to micelles, shrinkage/stretching of micelles, and morphological transition from spherical micelles to vesicles. ${ }^{[161]}$ Similar transitions could be obtained by decreasing the solvent quality using various acetone/water mixtures (Figure 14). ${ }^{[157]}$ 


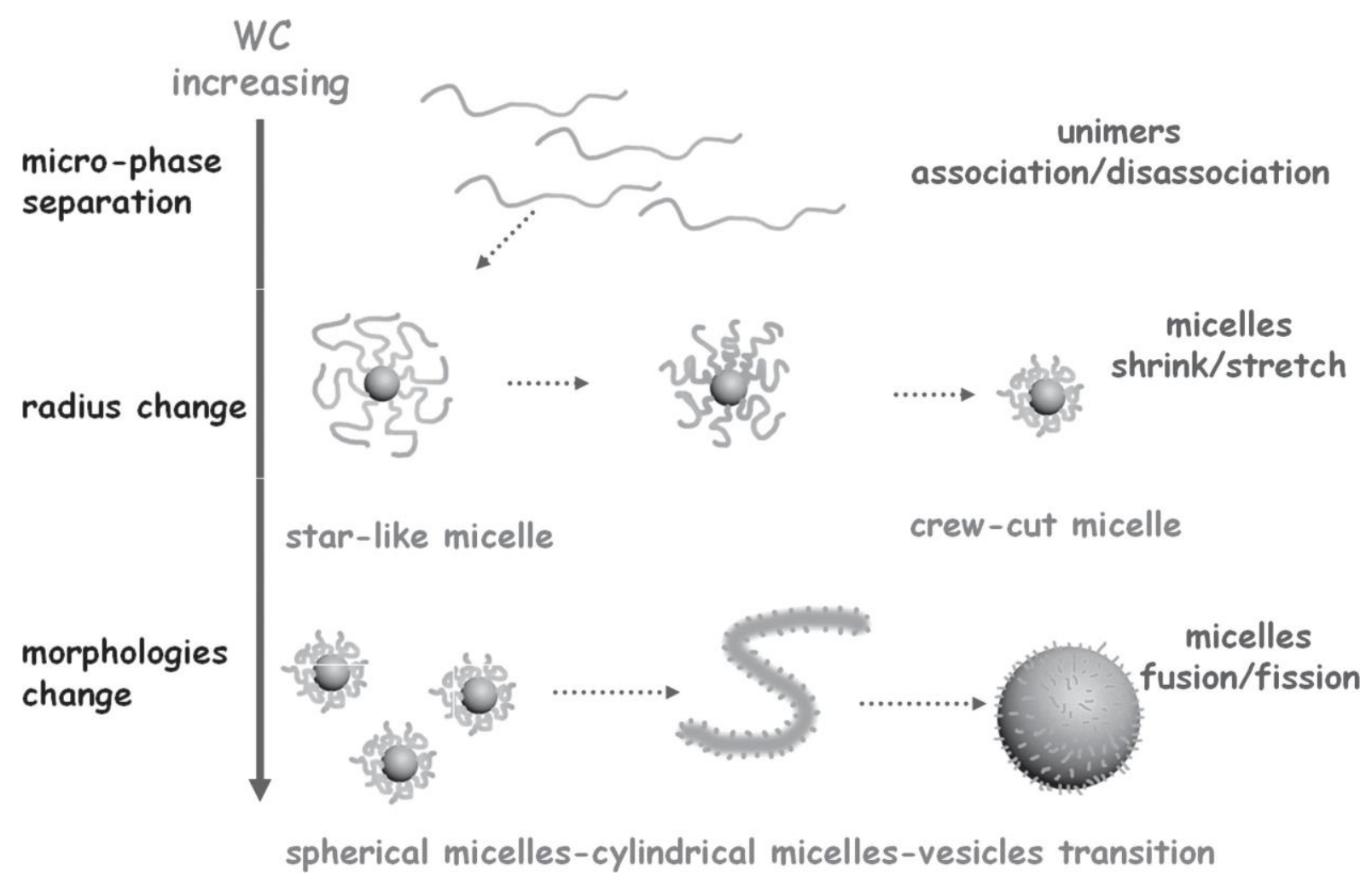

Figure 14. Schematic illustration of the overall transitions of the gradient copolymer micellar system via increasing the water content (WC) in acetone-water mixtures: a unimers to micelles transition; a star-like micelles to crew-cut micelles transition; and a morphological transition from spherical micelles to cylindrical micelles to vesicles. Reproduced from reference: Zheng et al. ${ }^{[157]}$ (C) 2013 WILEY-VCH Verlag GmbH \& Co. KGaA, Weinheim

Critical micelle concentration and cloud point. Several experimental and theoretical studies have shown that gradient copolymers display substantially higher CMCs than their corresponding block copolymers; amphiphilic block copolymers form aggregates more readily due to the presence of longer hydrophobic segments and greater contrast in hydrophobicity. ${ }^{[22,}$ 114, 165, 168-171] Due to the broader distribution of monomer units along the polymer chain, the CMCs of gradient copolymers are also more sensitive to variation in hydrophobic content than those of block copolymers. ${ }^{[123]}$

In aqueous solution, the cloud point $(\mathrm{CP})$ temperatures of gradient copolymers are typically intermediate between those of the corresponding block and statistical copolymers. ${ }^{[105,123,128]}$ CPs of gradients are also more sensitive to changes in polymer hydrophilic content than those 
of blocks. ${ }^{[123]}$ Meanwhile, the onset of clouding in dilute aqueous solutions of gradients occurs at lower temperatures with increasing monomer segregation, while the breadth of the transition decreases, suggesting that the macroscopic CP transition is highly sensitive to co-monomer sequence distribution of the copolymers. ${ }^{[120,172]}$ These observations indicate that the onset of clouding is determined by the temperature when the less soluble segment of the polymer chain precipitates from solution. ${ }^{[120]}$

Asymmetric copolymers are more soluble in $\mathrm{scCO}_{2}$ at lower temperature and pressure, and display lower CP pressures than related block copolymer analogues. ${ }^{[22,168]}$ Interestingly, amphiphilic vinyl ester based spontaneous gradient copolymers display faster equilibration at the water $/ \mathrm{CO}_{2}$ interface than analogous block copolymers. ${ }^{[22]}$ The higher compatibility between the two polymer segments facilitates diffusion of the copolymer to the interface and also results in lower interfacial tension.

\subsection{Self-assembly in bulk and thin films}

In the bulk state, asymmetric copolymers display different thermal and phase separation properties to their block counterparts. ${ }^{[173]}$ The mixing of monomers within the chain leads to a higher compatibility of the two phases, resulting in decreased heterogeneity at the domain interface which lowers the effective enthalpic interaction parameter, $\chi \cdot^{[174]}$ As a result, the sinusoidal density profiles predicted for lamellar structures of gradient polymers resemble those predicted for weakly segregating block copolymers (Figure 15). ${ }^{[2]}$ 


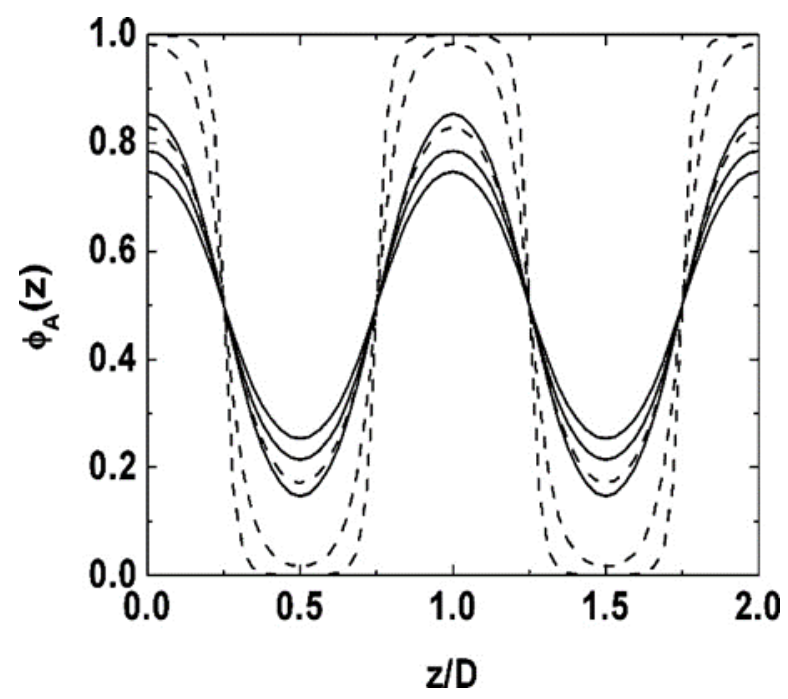

Figure 15. Density profile for $A$ monomers in the lamellar structure at $f_{\mathrm{A}}=0.5$. The solid lines are the multiblock SCFT results for a linear gradient copolymer melt (at $z=0$, from bottom to top, the profiles correspond to $\chi N=$ 40, 50, and 140). The dashed lines are the SCFT results for a diblock copolymer melt (at $z=0$, from bottom to top, the profiles correspond to $\chi N=12,20$, and 50). The period of the lamellar structure is $D$. Adapted from Jiang et al. ${ }^{[2]}$ Copyright $(2) 2008$ American Chemical Society

Shi and co-workers demonstrated that the minimum order-disorder transition temperature (ODT) for gradient copolymers varies as a function of the degree of monomer segregation, and becomes higher as the monomers are more uniformly mixed. ${ }^{[2]}$ More segregated copolymers display ordered domain spacing while gradient copolymers with smoother transitional profiles display disrupted self-assembly behavior resulting in poorly ordered domains. ${ }^{[175]}$ This difference is attributed to the longer transition sequence profile with the smoother gradient and resultant decrease in $\chi$.

The gradient profile of gradient copolymers affects phase behavior, resulting in both ordering and disordering phase transitions at different temperatures. Shifts of phase behavior due to changes in molar mass are more pronounced in gradient copolymers compared to their block counterparts. ${ }^{[176]}$

The incomplete phase separation predicted for asymmetric copolymers has been observed using a number of experimental techniques. Fast and slow magic-angle spinning NMR coupled with a spin-counting strategy has been used to quantify the hard and soft phases in 
styrene-butadiene gradient copolymers. ${ }^{[27]}$ The method allowed the amount of low- $T_{\mathrm{g}}$, or "soft", butadiene component that is incorporated into the rigid domains to be determined, as well as the amount of high- $T_{\mathrm{g}}$, or "hard", styrene component in the mobile domains. This study showed differential phase partitioning in gradient copolymers but not in an analogous block system.

Low-amplitude oscillatory shear measurements and small-angle X-ray scattering (SAXS) studies showed that in a strongly segregated system a high molar mass gradient copolymer exhibited a behavior similar to a highly microphase segregated block copolymer analogue, while a lower molar mass gradient copolymer exhibited a complex, nonterminal behavior indicative of a lower degree of microphase segregation. In less segregated systems, gradient copolymers yielded a more liquid-like behavior, with a low molar mass sample exhibiting nearNewtonian behavior, indicative of a weakly segregating structure, while a high molar mass sample with a steeper gradient showed behaviors ranging from solid-like to more liquid-like with increasing temperature. Both rheology and SAXS provided evidence of shear alignment, despite the gradual variation in composition profile across the nanodomains of the investigated samples. ${ }^{[110]}$

A strong driving force for phase segregation leads annealed thin films of block copolymers to present an island/hole surface topography. However, for gradient copolymers, the weaker segregation results in either no pattern development, or island/hole patterns that coarsen upon initial annealing that are subsequently lost after prolonged annealing times. ${ }^{[109]}$

Differences in the degree of phase separation were directly observed by atomic force microscopy for semi-crystalline copolymers of 3-hexylthiophene and 3-hexylselenophene. ${ }^{[17]}$ Gradient copolymers exhibited less pronounced phase separation than block copolymers but significantly more than analogous random copolymers (see Figure 16$)^{[80,117]}$ It was also observed that the block copolymer melted at a higher temperature than the gradient copolymer 
and the random copolymer, implying that the solid-state packing of the block copolymer may be more stable than that of the gradient and random copolymers, which may indicate a more phase-separated morphology. ${ }^{[117]}$ Due to the gradual change of composition in the backbone of asymmetric copolymers, phase boundaries in the bulk state are often "blurred" and poorly defined.$^{[177]}$
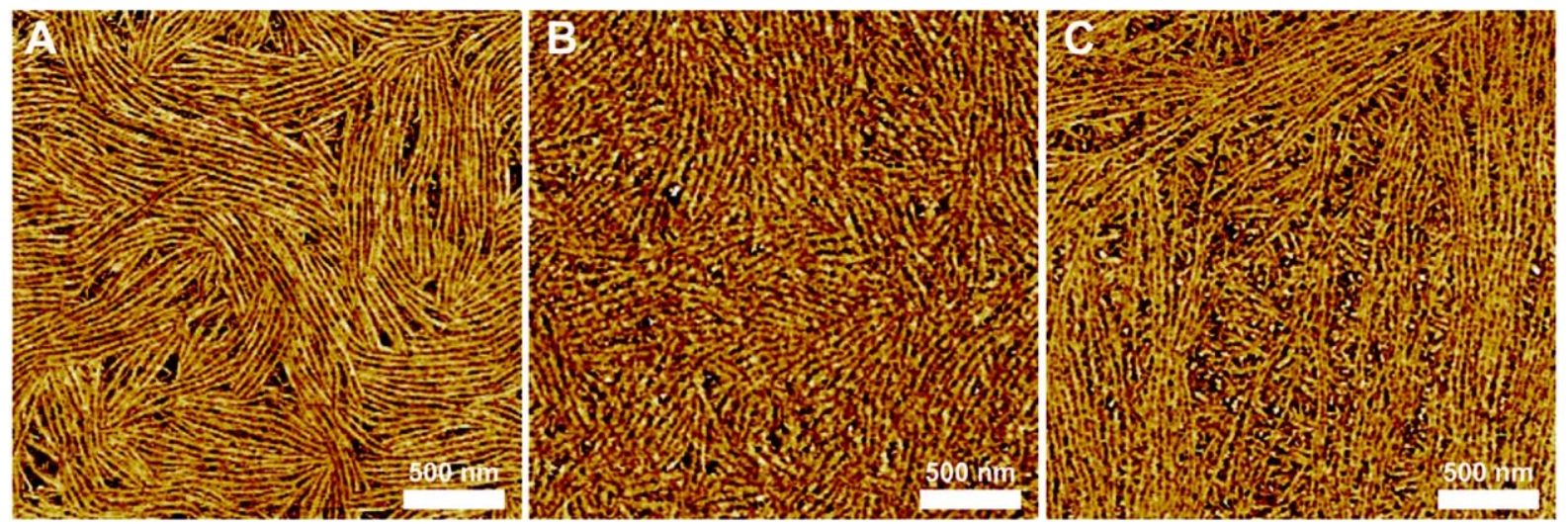

Figure 16. Tapping mode atomic force microscopy (AFM) phase images of (A) block, (B) gradient, and (C) random copolymer thin films after isothermal recrystallization demonstrating the extent and nature of lamellar formation, which was greatest in the block copolymer, followed by the gradient copolymer and weakest in the random copolymer. Adapted from Palermo et al. ${ }^{[117]}$. Copyright $@ 2012$ American Chemical Society

Glass Transition. One of the best known properties of gradient copolymers is that they often display a single broad glass transition temperature. ${ }^{[17,78,80,130,178-182]}$ In contrast, analogous block copolymers typically show a separate glass transition temperature for each of their block components due to nanophase separation into ordered micro-domains, ${ }^{[23,183]}$ while statistical copolymers show a single, narrow glass transition temperature. ${ }^{[178,180,182]}$ The broad $T_{\mathrm{g}}$ observed for gradients is a direct result of incomplete microphase segregation, which leads to a compositionally heterogeneous bulk material containing a wide range of dynamic environments (Figure 17) (Figure 17). ${ }^{[5,184]}$ In contrast, statistical and block copolymers form relatively homogeneous structures containing only one (statistical) or two (block) types of dynamic environment ${ }^{[184]}$ 

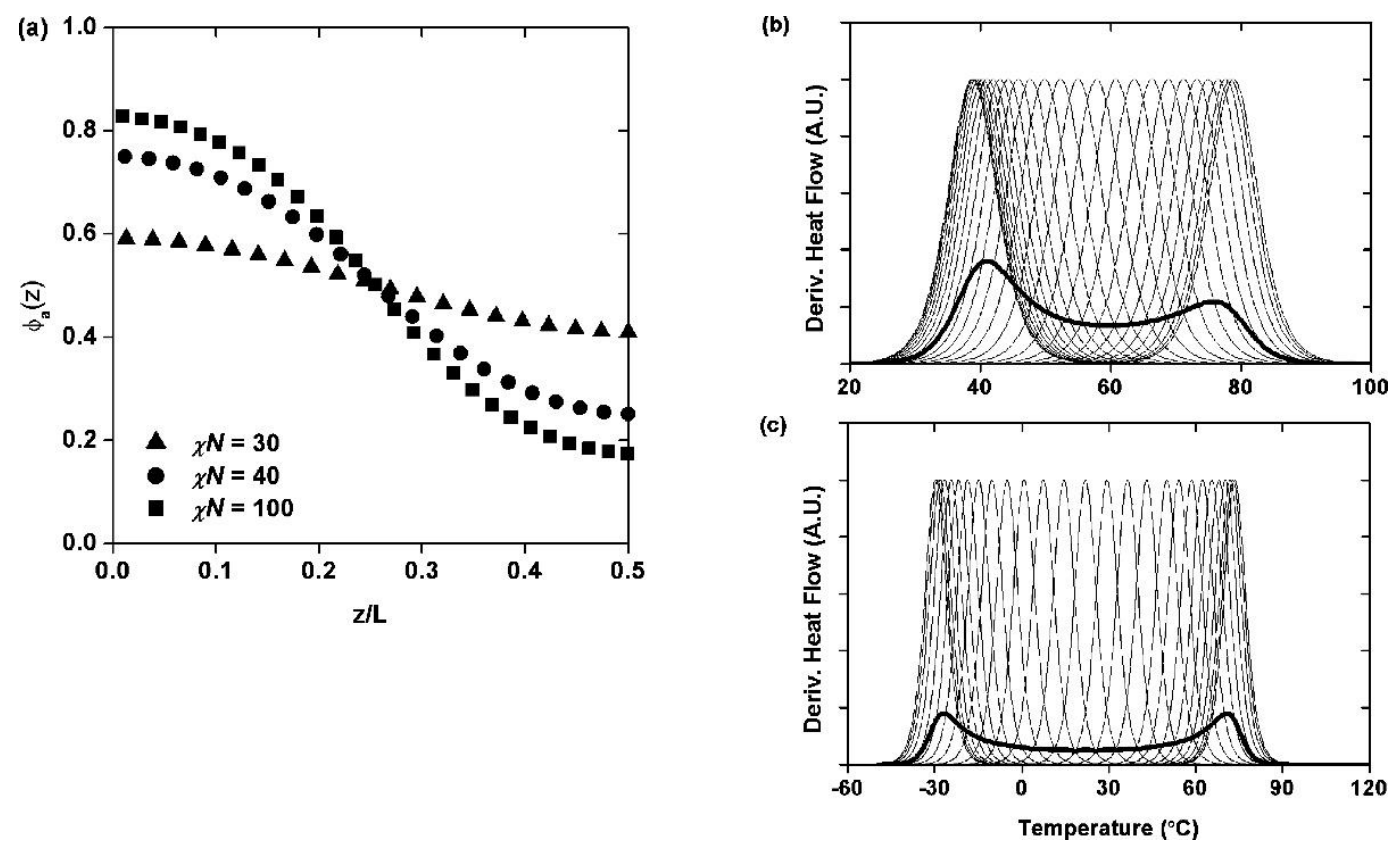

Figure 17. (a) Equilibrium lamellar compositions for a symmetric linear gradient copolymer calculated at $\chi \mathrm{N}=30$, 40, and 100 using SCMF techniques. The period of the lamellar structure is L. Predicted DSC derivative heat flow curves for (b) S/BMA and (c) S/nBA linear gradient copolymers with $\chi \mathrm{N}=100$. The thin lines are the derivative heat flow traces corresponding to copolymers with the composition fractions predicted in the composition profile, while the bold line is the area-normalized summation of the individual composition fraction traces. (Note: material-specific heat capacities were not accounted for in these predictions.) Reproduced from Mok MM et al, ${ }^{[5]}$. Copyright (C) 2009 American Chemical Society

For example, $T_{\mathrm{g}}$ breadths of the order of $69-71{ }^{\circ} \mathrm{C}$ were observed for styrene/ $n$-butyl acrylate and styrene/hydroxystyrene gradient copolymers. ${ }^{[185]}$ The $T_{\mathrm{g}}$ breadth was also found to continuously widen with the increasing change of the gradient composition; ${ }^{[178]}$ it can be tuned by varying the chain length, identity of comonomers, and the strength of composition gradient. ${ }^{[108]}$ Dynamic mechanical analysis on the temperature dependences of the storage and loss moduli and $\tan \delta$ of copolymers of different sequences also demonstrated that gradient copolymers can show a glass transition breadth at least four times larger than random copolymers. Investigations on the effect of gradient steepness in styrene/ $n$-butyl acrylate gradient copolymers showed that broader glass transitions were obtained for copolymers with greater variation in composition along the polymer chain. ${ }^{[108]}$ Gradient copolymers also showed broader dielectric relaxation time ${ }^{[186]}$ and broader enthalpy recovery peaks ${ }^{[187]}$ compared to 
corresponding random copolymers. As materials absorb mechanical energy most effectively at their glass transition temperature, gradient copolymers may have technological applications in sound and vibration damping where broad and continuous glass transition behaviour is highly desired.

\section{Applications of asymmetric copolymers}

Asymmetric copolymers have been proposed for applications (summarized as Figure 18) ranging from modifying the properties of homopolymer interfaces, ${ }^{[169]}$ compatibilization of immiscible homopolymer blends, ${ }^{[73,74,}{ }^{188]}$ utilization as nanocarriers of compounds of pharmaceutical interest, ${ }^{[30,32]}$ as complexing surfactants for the extraction of metal derivatives in $\mathrm{scCO}_{2}{ }^{[61]}$ and as polymeric sensors for solvent polarity ${ }^{[189]}$ due to the dynamic self-assembly behavior depending on the solution environment, to constructing thermosensitive bioconjugates and drug delivery systems. ${ }^{[190]}$

Asymmetric copolymers can also be used as oil/water separation membranes, ${ }^{[122]}$ sound and vibration damping materials, ${ }^{[178]}$ thermoplastic elastomers, ${ }^{[81]}$ shape memory materials, ${ }^{[191]}$ adaptive solar control materials, ${ }^{[192]}$ and polymer electrolyte. ${ }^{[79]}$ However, to date, few of these applications have been effectively realized. In the following section, some experimental examples demonstrating the potential applications of asymmetric copolymers are summarized. 


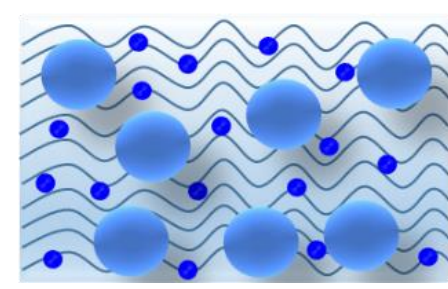

Compatibilizers in polymer blends
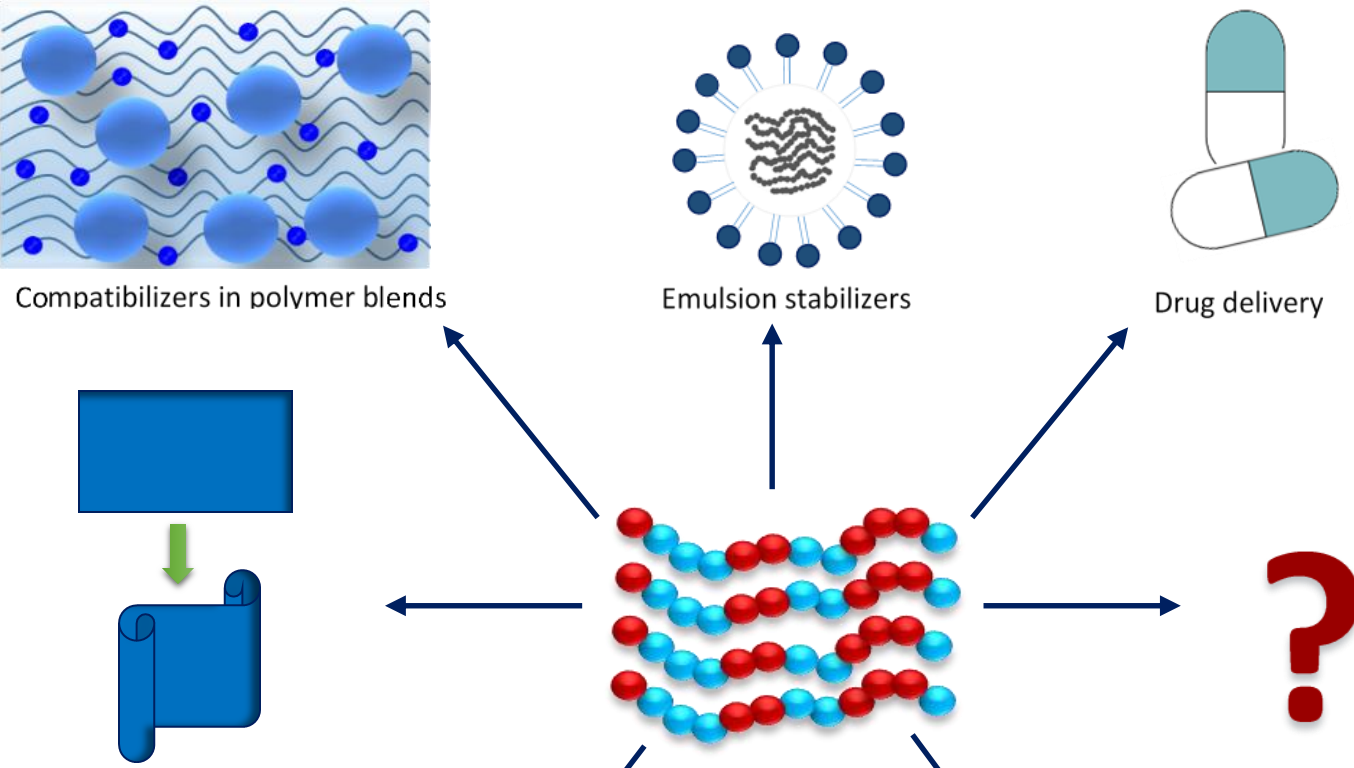

Shape memory materials

Emulsion stabilizers

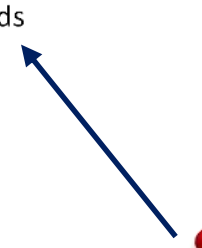

(1)

Drug delivery

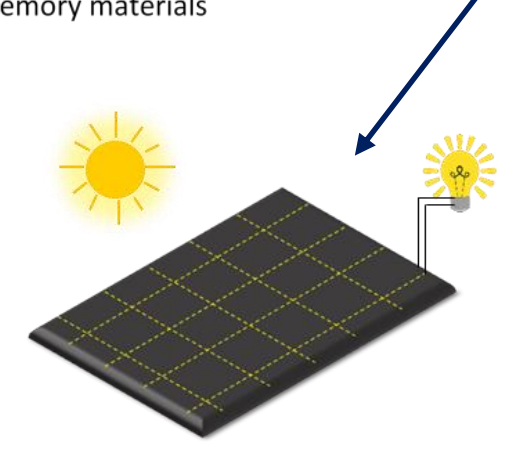

Photovoltaic systems
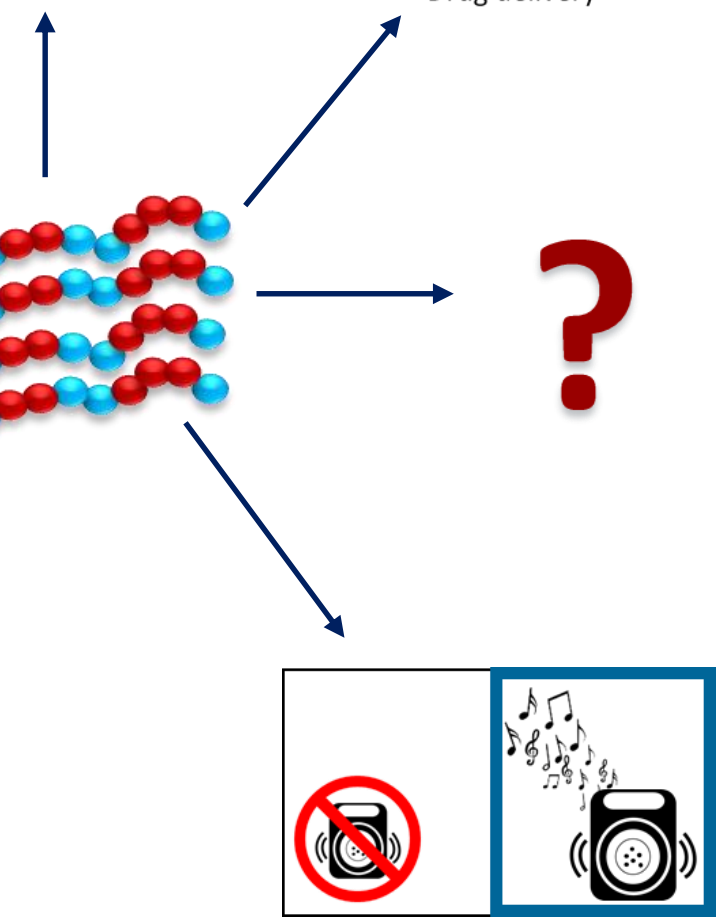

Acoustic damping

Figure 18. Examples of applications of asymmetric copolymers.

\subsection{Compatibilizers in immiscible polymer blends}

Blending of immiscible polymers or adding fillers to polymeric matrix ${ }^{[193-196]}$ allows systematic tuning of material properties, but compatibilizing the component polymers remains a significant challenge. ${ }^{[197]}$ In this context, theoretical studies of gradient copolymers suggest that they should be attractive materials for altering the interfacial properties of the blends of immiscible homopolymers. ${ }^{[169,198]}$ Their significantly higher CMC values (less likely to be trapped in micelles) and broader interfacial coverage (which will greatly reduce the interfacial tension) compared to analogous block copolymers are advantageous for compatibilizing immiscible blends. ${ }^{[74,111,113,188]}$

Torkelson and co-workers have demonstrated that gradient copolymer addition is a viable strategy for compatibilization of melt-processed polymer blends and suggested that the success 
of this strategy depends significantly on both the overall composition of the gradient copolymer and the inherent incompatibility of the blend. ${ }^{[74,111,113]}$ For instance, a specific study on polystyrene/polycaprolactone blends reports the evaluation of copolymers of different sequence (i.e., block, blocky gradient, or blocky random copolymer) as compatibilizers, where it was found that the interfacial tension and crystallinity of the blend greatly depend on the level of copolymer compatibilizer, in addition to its sequence distribution and composition. ${ }^{[73]}$ The use of $\pi$-conjugated gradient copolymers as compatibilizers in polymer blends of 3hexylthiophene (3HT) and 3-(6-bromohexyl)thiophene (3BrHT) has been also reported. ${ }^{[118,119]}$ Thermally annealed physical blends of these homopolymers showed extensive micro-scale phase separation, while by adding a gradient copolymer to the blend resulted in a dramatic reduction in the domain size. By comparison, the random and block copolymers analogous materials were less effective compatibilizing agents, which strongly suggested that a gradient copolymer is well suited to tailor the morphology of immiscible polymer blends (Figure $19) .^{[118]}$ 

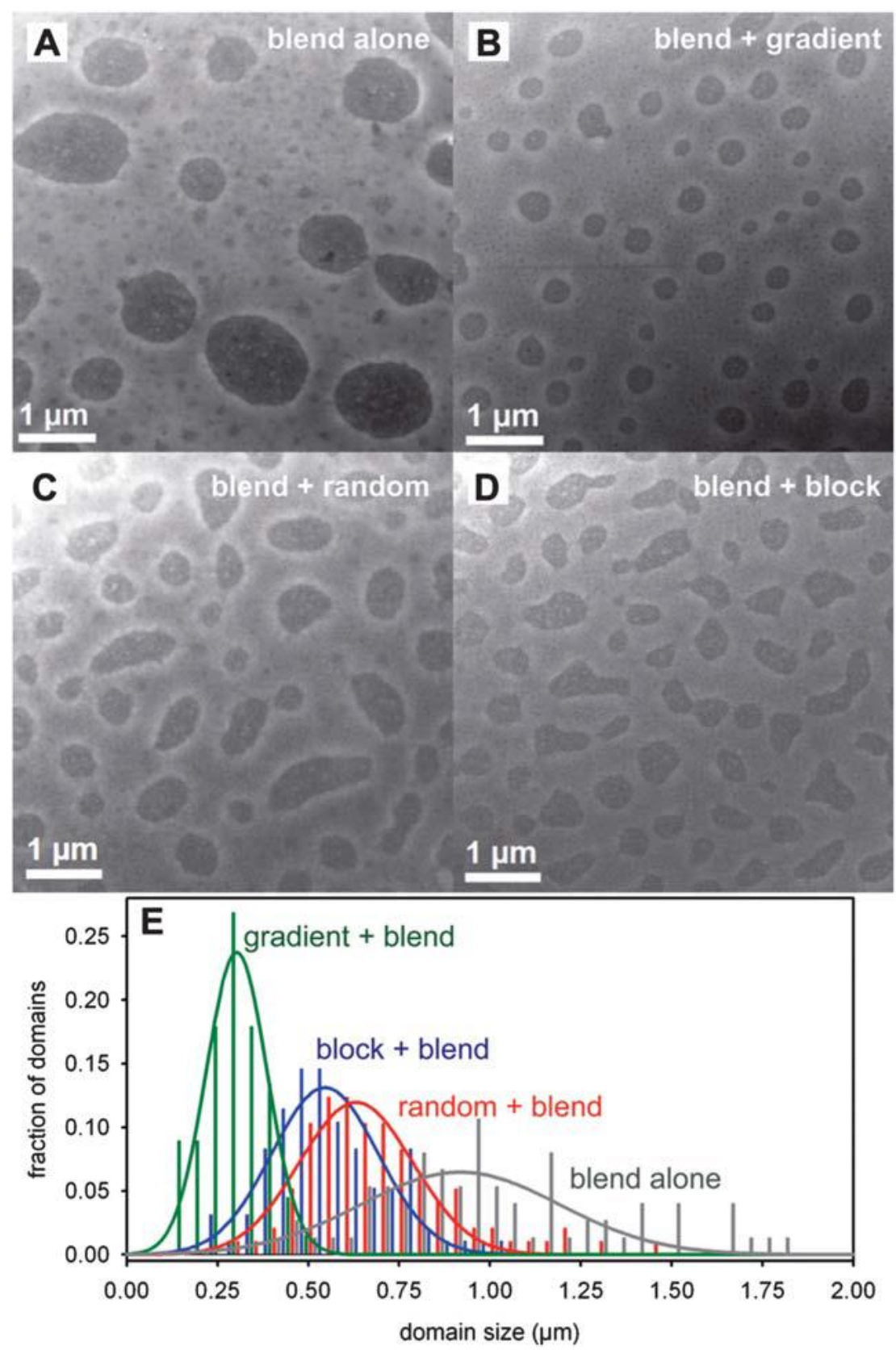

Figure 19. STEM images of the $1: 1(\mathrm{v} / \mathrm{v})$ P3HT-P3BrHT blend (A) without copolymer additive, (B) with 20 wt\% gradient copolymer, (C) with $20 \mathrm{wt} \%$ random copolymer, (D) with $20 \mathrm{wt} \%$ block copolymer. (E) Histogram of the domain size distributions. Reproduced from Palermo et al, ${ }^{[118]}$ with permission of the Royal Society of Chemistry. http://dx.doi.org/10.1039/C3PY00601H

\subsection{Stabilizers in heterogeneous polymerizations}

It has been shown that amphiphilic gradient copolymers can be more effective interfacial modifiers in organic-aqueous interphases as compared to their analogous block copolymers of similar molar mass and overall composition. ${ }^{[106]}$ 
In this context, gradient copolymers can act as efficient stabilizers in (mini-)emulsion polymerization $^{[49]}$ or non-aqueous dispersion polymerization ${ }^{[199]}$ where latexes with a narrow particle distribution can be obtained. ${ }^{[200]}$ Even though the performance of gradient copolymers as stabilizers in heterogeneous polymerizations might not be always superior to that one observed for the analogous diblock copolymer materials, gradient copolymers have been regarded as attractive alternatives for this application due to their potentially simpler preparation procedure. ${ }^{[49]}$

Amphiphilic gradient copolymers bearing $\mathrm{pH}$-sensitive co-monomer units can show a dynamic self-assembly nature and have been proposed as efficient and low-cost $\mathrm{pH}$-responsive rheology modifiers in aqueous solutions. ${ }^{[151]}$

\subsection{Membranes}

A polyelectrolyte composed of a gradient amphiphilic copolymer has been ionically crosslinked and used for the preparation of a 2-D self-assembled membrane at an oil/water interface. While ionically crosslinked membranes of analogous block copolymer materials were critically damaged after one expansion cycle, the membrane composed of a gradient copolymer displayed a higher physical integrity through multiple expansion-compressionexpansion cycles. This superior mechanical behavior was attributed to the more effective properties of gradient copolymers as interfacial modifiers, which might have a significantly different molecular alignment at the oil/water interface. ${ }^{[107]}$

Amphiphilic fluorinated gradient copolymers of ethylene glycol methyl ether methacrylate (EGMA) and 3,3,4,4,5,5,6,6,7,7,8,8,8-tridecafluorooctyl acrylate (TFOA), P(PEG-gradTFOA), were utilized to fabricate poly(ether sulfone) (PES) blended membranes via a nonsolvent-induced phase separation method. During the phase inversion process, the fluorinated gradient copolymer formed an amphiphilic surface on the membranes, which was demonstrated by surface wetting properties and X-ray photoelectron spectroscopy (XPS) measurements. 
Based on filtration experiments of an oil-in-water emulsion, the heterogeneous membranes exhibited superior oil-fouling resistant properties (i.e., low flux decay and high flux recovery) as compared to the pure PES membrane. The synergistic effect of fouling-resistant and foulingrelease mechanisms was found to be responsible for the excellent antifouling capacities, which might be used for effective oil/water separation membranes (Figure 20). ${ }^{[122]}$

\section{Synergetic-defense mechanisms}

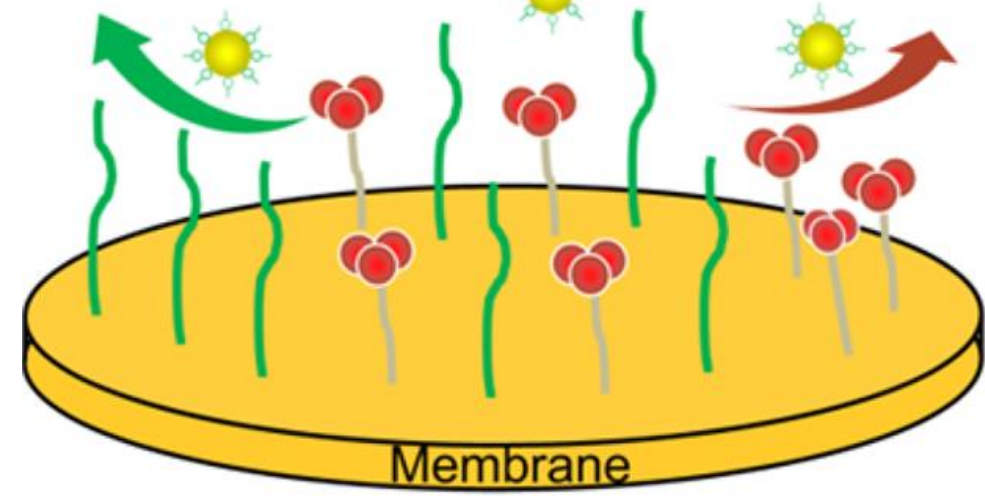

Fouling-resistant mechanism Fouling-release mechanism

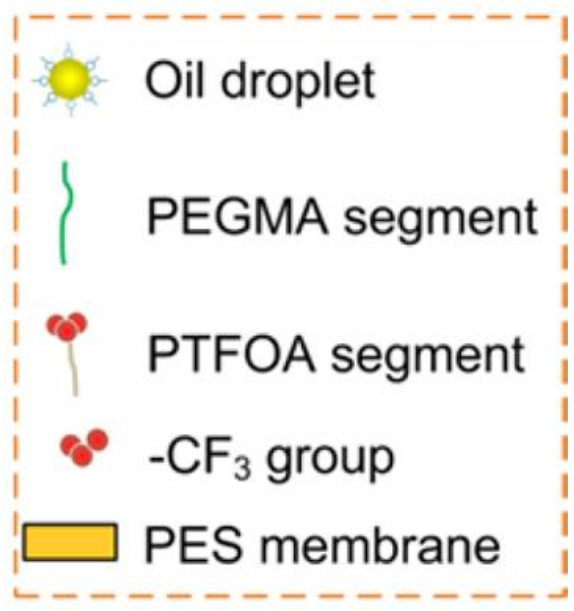

Figure 20. Schematic illustration of synergetic-defense mechanisms for heterogeneous PES membrane. Adapted with permission from Zhang et al. ${ }^{[122]}$ Copyright (C) 2016 American Chemical Society

\subsection{Damping applications}

Materials with a broad glass transition are highly desirable in vibration and acoustic damping applications. Gradient copolymers with different degrees of incompatibility and gradient steepness can be tailored to exhibit broad and continuous glass transitions, and are therefore attractive candidate materials in this context.

The temperature dependences of the storage modulus (E'), loss modulus (E''), and $\tan \delta$ of the materials analyzed by dynamic mechanical analysis (DMA) have revealed that the gradient copolymers exhibit greater potential for damping applications as compared to statistical and block copolymers with similar overall composition, length, and compositional profiles. This is 
because gradient copolymers can display nano-heterogeneous morphologies and wide array of local compositions which facilitates energy dissipation over a wider temperature range. ${ }^{[108]}$

\subsection{Shape memory materials}

A V-shaped styrene-butadiene-styrene (SBS) gradient copolymer has been demonstrated to be an efficient multishape memory polymer. ${ }^{[191]}$ This V-shaped gradient copolymer (Figure 21b) chain is composed of low- $T_{\mathrm{g}}$ units at the center and gradually changes its composition with higher- $T_{\mathrm{g}}$ units towards the polymer chain ends. The nano domains with the highest $T_{\mathrm{g}}$ are surrounded by nano domains with decreasing $T_{\mathrm{g}}$ in a layer-by-layer format (Figure $21 \mathrm{~b}$ ). This diffuse transition differs from block copolymers, which have well-defined phase separation and distinct transitions (Figure 21c). The gradient-transition feature allows the multishapememory effect because the innermost chain segments constitute the nanodomains with the highest $T_{\mathrm{g}}$, which acts as the network to prevent chain relaxation, while the surrounding nanodomain layers with gradient $T_{\mathrm{g}}$ transitions hold the temporary shapes and trigger the shape recovery at different temperatures. Hence, the linear and V-shaped compositional gradient copolymers showed lower elastic modulus, much larger elongation at break, but similar ultimate tensile strength as compared to block analogues. This performance was ascribed to that the local moduli continuously vary from the hardest nanodomains to the softest nanodomains in the gradient copolymer, which alleviates the stress concentration during tensile tests. Compared to the V-shaped gradient copolymer, the linear gradient copolymer showed much higher elastic modulus but lower elongation at break due to better phase compatibility in the $\mathrm{V}$-shaped gradient copolymer. The mechanical properties of the gradient copolymers were also found to be more sensitive to changes in temperature than their block copolymer counterparts. ${ }^{[201]}$ 


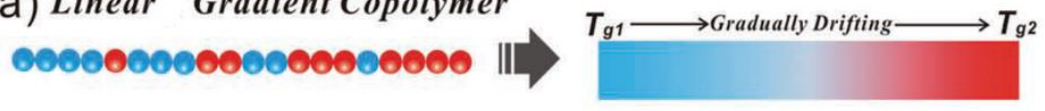

b) V-shaped Gradient Copolymer
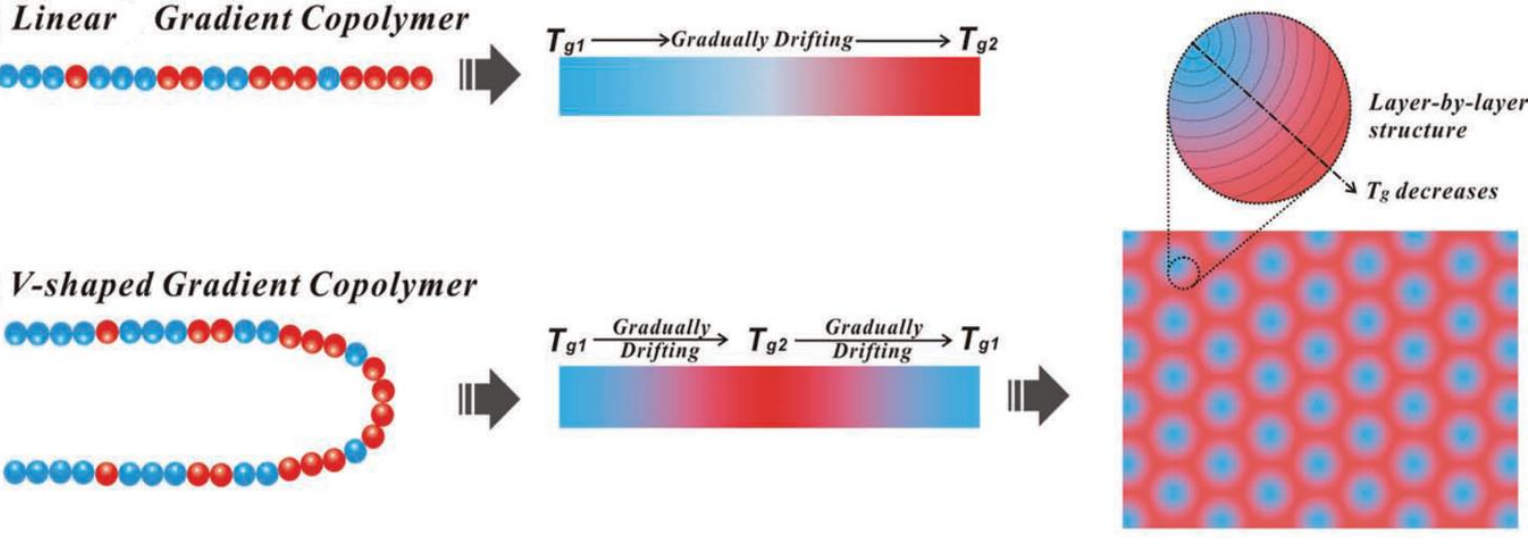

C) SBS Triblock Copolymer
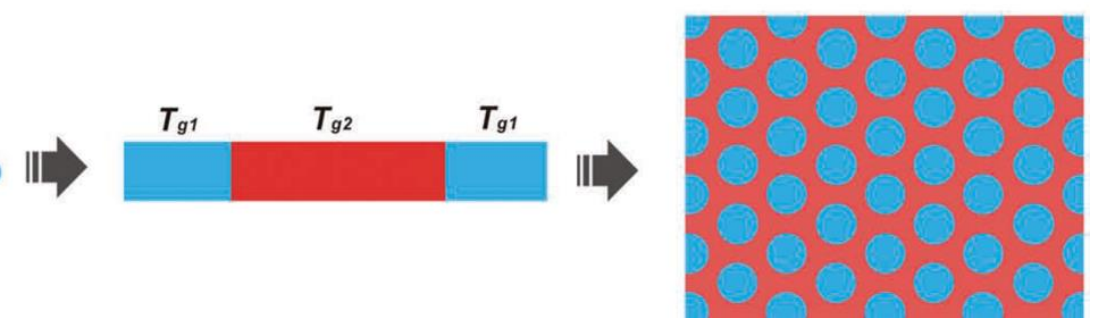

Figure 21. The molecular design strategy of the multishape-memory polymer. a) Chain architecture of linear gradient copolymer. b) Chain architecture and microphase separation of V-shaped gradient copolymer. c) Chain architecture and microphase separation of the SBS triblock copolymer. Reproduced from Luo et al. ${ }^{[191]} \odot 2013$ WILEY-VCH Verlag GmbH \& Co. KGaA, Weinheim

\subsection{Photovoltaic systems (solar cells) and conductive materials}

As mentioned above, the copolymer sequence can significantly influence the solid-state organization of semi-crystalline polymers. ${ }^{[117]}$ In this context, $\pi$-conjugated gradient copolymers can exhibit an extent of phase separation and domain segregation that is intermediate between that of block and random copolymers and, hence, provide access to new morphologies for various applications. Since morphology is an important factor in optoelectronic applications, it has been demonstrated that $\pi$-conjugated and semi-crystalline forced gradient copolymers lead to improved device performance in polymer-based solar cells. $^{[16]}$

Block copolymers have a tendency to strongly self-assemble into dense clusters of purecopolymer rich regions, reducing the copolymer interfacial area within devices. Conversely, gradient sequences disrupt this innate self-assembly characteristic of copolymers, promoting interfacial interaction between the copolymer and the rest of the components of the device. 
This results in a more continuous, interconnected fibrillar morphology when compared to analogous block copolymer systems, resulting in higher initial carrier density. ${ }^{[16]}$ Based on theoretical investigations, it was suggested that by utilizing gradient copolymers (or by layering copolymers of differing constant monomer ratio in a graded fashion), a gradient in the electronic structure and properties of $\pi$-conjugated polymers can be achieved. ${ }^{[202]}$
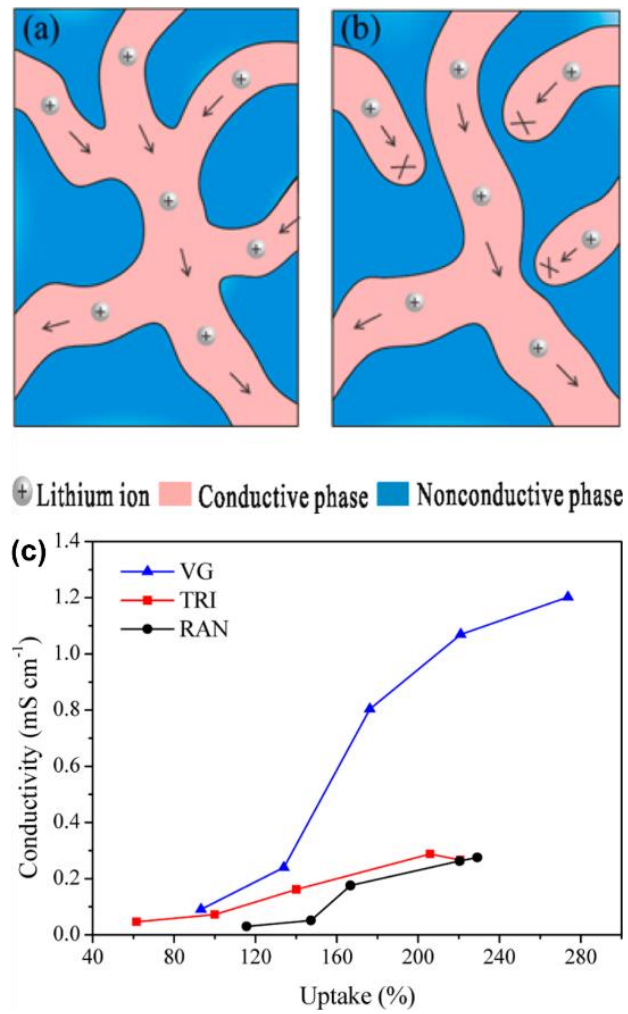

Figure 22. (a) Illustration of continuous conducting pathways. (b) Illustration of pathways with dead ends. (c) Dependence of conductivity on the liquid electrolyte uptake in the V-shape gradient copolymers (VG), triblock copolymers (TRI), and random copolymers (RAN). Adapted from Zheng et al. ${ }^{[79]}$ Copyright $\odot 2016$ American Chemical Society

As liquid electrolytes containing flammable esters or ethers raise severe concerns of leakage, ${ }^{[203]}$ solid electrolytes have attracted significant attention as potential alternatives. ${ }^{[204,}$ ${ }^{205]}$ Thus, the use of gradient copolymers as a new type of polymer electrolyte has been proposed to overcome limitations in terms of low ionic conductivity typically encountered in polymer electrolytes. The continuous ionic conducting pathways which are usually circuitous are formed by connecting polar conductive domains in a film (Figure 22a). In block 
copolymers, strong phase separation and well-defined domain boundaries always exist and, therefore, numerous dead ends will be formed because the nonpolar domains could isolate some polar pathways; this will significantly affect the ion conduction (Figure 22b). Gradient copolymers show phase separation but give no abrupt composition change between the adjacent blocks, displaying a highly continuous morphology, therefore more continuous and smoother ion conducting pathways for the fast and efficient ion transport were formed as compared to block and random copolymers analogous (Figure 22c). ${ }^{[79]}$

\subsection{Patented applications}

In the industrial sphere, a number of patent applications have been filed disclosing the use of gradient copolymers. These applications mainly focus on the use of gradient copolymers as dispersants or emulsifying agents, as adhesives, and as components in personal care products such as hairsprays or skin creams.

Dispersants or emulsifying agents. Arkema has disclosed a method for the preparation of amphiphilic gradient copolymers prepared by RDRP. In a specific example, it is claimed that a RAFT St/AA gradient copolymer system has improved properties as a dispersant due to a better homogeneity of copolymer composition and lower dispersity as compared to commercial products. This was exemplified with high solid content aqueous dispersions of low viscosity in an alkaline medium and with the design of an efficient reactive stabilizer, which can be used at low concentration in emulsion polymerization processes. ${ }^{[206,207]}$

BYK-Chemie patented the use of forced gradient copolymers prepared by ATRP, with a transition from hydrophilic to hydrophobic along the polymer chain, as dispersing agents of different compounds (including pigments and fillers); the resulting dispersions can be utilized in coating compositions, pastes and/or moulding compounds comprising. ${ }^{[208]}$ The disclosed gradient copolymers provided better dispersions with a low propensity to foam, which particularly in coating compositions do not give rise to any blemishes, while simultaneously 
featuring high gloss and good transparency. Several comparative examples with diblock and statistical copolymers analogues were analysed for paint applications.

Sika Technology recently reported the use of RAFT-derived PEGMA/AMA forced gradient copolymers as dispersing agents for use in a binding composition for construction materials applications. It was shown that gradient copolymers have a better performance than analogue diblock or statistical copolymers. ${ }^{[209,210]}$

Rohm and Haas recently disclosed the preparation of aqueous compositions for use as elastomeric roof coatings having excellent tint retention which comprise of one (or more) gradient emulsion copolymers having a weight average particle size of from 20 to $550 \mathrm{~nm}$, a filler (e.g., silica) and chromatic colorants or other pigments. This invention provides methods of making the one or more gradient emulsion copolymers having a broad measured glass transition temperature $\left(T_{\mathrm{g}}\right){ }^{[211]}$ In this context China Petroleum has also recently disclosed methods for preparing gradient copolymers capable of exhibiting excellent lubricating oil pour point depression efficiency or a wide base oil pour point depression adaptability. ${ }^{[212]}$

Rohmax Additives has also patented methods for the preparation of diverse gradient copolymers and the use of these materials as additives in lubricant oils containing different formulation ingredients. ${ }^{[213]}$

Adhesives/fixatives/hairsprays. Arkema has also claimed the one-pot synthesis of different acidic functionalized gradient block copolymers (e.g., triblock copolymers with outer blocks of gradient microstructure) with potential applications as hair fixatives, toughening agents and adhesives. ${ }^{[214]}$ Aqueous dispersions of spontaneous amphiphilic gradient copolymers derived from NMP were reported to be useful in surface treatment techniques and can be used in formulations for adhesives, glues as well as in cosmetics. ${ }^{[215,216]}$

L'Oréal used the benefits associated with gradient copolymers of low dispersity to prevent problems of phase separation often encountered in blends of polymers or random copolymers 
with heterogeneous compositions. They used NMP-derived St/Acrylate/AMA gradient copolymers of Arkema and took advantage of their better dissolution/dispersion in water and in polar organic solvents to claim film-forming compositions with a good sprayability for aerosol compositions, and good adhesion and mechanical properties for nail varnish compositions. Similar copolymers were also used for a skin-tightening effect ${ }^{[217-220]}$ and skin hydration $^{[221]}$ as formulation additives in anti-wrinkling creams. Better compatibility and solubility in organic media formulations were also claimed for makeup applications, with ATRP-derived spontaneous gradient copolymers made of isobornyl methacrylate and various acrylate comonomers. ${ }^{[222,223]}$ However, no comparative examples using block or statistical copolymer analogues to the gradient copolymers are provided in these patents.

Kuraray disclosed hot-melt adhesive compositions based on gradient copolymers having good melt processability, holding power, good weather resistance, adhesiveness at low temperature and transparency. ${ }^{[24]}$ The nBA/MMA-based copolymers of this technological development were prepared via living anionic polymerization taking advantage of that fact that $\mathrm{nBA}$ is more reactive than MMA under this reaction mechanism, which will lead to the formation of spontaneous PMMA- $b$-P(nBA-grad-MMA)- $b$-PMMA copolymers in a two-stage process. Comparative examples using block copolymer analogues to the gradient copolymers are disclosed in this patent.

\section{Conclusions}

The unique monomer microstructures of asymmetric copolymers (mostly through gradient copolymers) have attracted considerable attention. In this review we have argued that rather than focusing on the changing monomer composition as a function of chain length, which is impossible to observe at the level of an individual chain, it is preferable to focus on the distribution of monomers within individual chains. Thus chains with perfectly segregated

monomers are classed as block copolymers, chains whose monomers are statistically 
distributed independently of their position in the chain are classed as statistical copolymers, and those that contain at least two segments of measurably different composition are classed as asymmetric copolymers. This classification includes gradient copolymers as well as block copolymers that contain statistical copolymer segments.

Thanks to the robustness of the many polymerization techniques discussed above, in addition to the availability of a large pool of functional monomers, a wide variety of asymmetric polymeric materials can readily be produced on demand. Asymmetric copolymers display intriguing properties such as dynamic self-assembly behavior in solution responding to environmental stimuli, higher CMC values than block copolymers, broader interfacial coverage, higher $\mathrm{CP}$ temperatures, unusually broad glass transition temperatures, and less pronounced phase separation. These properties result from the asymmetric monomer distribution, which has the effect of reducing the chemical incompatibility between the chain segments. In most cases, the properties of asymmetric copolymers resemble those of a weakly segregating block copolymer. The advantage of asymmetric copolymers is that the degree of asymmetry in the monomer distribution can be adjusted at will to form functional copolymers with a greater or lesser degree of chemical incompatibility between the different ends of the chain. By contrast, properties such as the 'reel-in' effect that can be assigned to the presence of multiple segments with gradually varying composition (i.e. a true composition gradient) are relatively rare.

Asymmetric copolymers have great potential for applications in modifying the properties of homopolymer interfaces, compatibilization of immiscible homopolymer blends, utilization as nanocarriers of compounds of pharmaceutical interest, polymeric sensors for solvent polarity, constructing thermosensitive bioconjugates and drug delivery systems, oil/water separation membranes, sound and vibration damping materials, thermoplastic elastomers, shape memory materials, adaptive solar control materials, and polymer electrolytes. Within the industrial 
sphere, patents making use of gradient copolymers have largely focused on applications as dispersants, emulsion stabilizers, and adhesives. However, with the exception of the gradient copolymer dispersants commercialized by BYK-Chemie, ${ }^{[208]}$ most of the proposed applications have not yet been realized as products and largely remain at the early stage of experimental development. We hope this review will serve as a guideline for the design and synthesis of asymmetric copolymers with precisely tuned properties and applications which can be applied in real life.

\section{Acknowledgements}

This research was financially supported by the ASYMCOPO Project, an international collaborative research project of the Deutsche Forschungsgemeinschaft (DFG, Germany) and the Agence Nationale de la Recherche (ANR, France); DFG project: GU 1685/1-1 (J. Z., C. G. S. and U. S. S.) and ANR project ANR-15-CE08-0039 (S. H.). C. G. S. and U. S. S. thank the Center for Excellence "PolyTarget" (SFB 1278, project Z01) of the Deutsche Forschungsgemeinschaft (DFG, Germany) for financial support. B. F. M. acknowledges the financial support from Consejo Nacional de Ciencia y Tecnologia (CONACyT, Mexico) to pursue her $\mathrm{PhD}$.

\section{Conflict of Interest}

The authors declare no conflict of interest.

\section{Keywords}

Asymmetric copolymers, gradient copolymers, block copolymers, statistical copolymers, copolymerization, reversible deactivation radical polymerization, living polymerization, selfassembly.

Received: Month XX, XXXX; Revised: Month XX, XXXX; Published online:

\section{References}


[1] U. Beginn, Colloid. Polym. Sci. 2008, 286, 1465.

[2] R. Jiang, Q. Jin, B. Li, D. Ding, R. A. Wickham, A.-C. Shi, Macromolecules 2008, 41, 5457.

[3] R. Wang, Y. Luo, B.-G. Li, S. Zhu, AIChE J. 2007, 53, 174.

[4] V. S. Kravchenko, I. I. Potemkin, J. Phys. Chem. B 2016, 120, 12211.

[5] M. M. Mok, J. Kim, C. L. H. Wong, S. R. Marrou, D. J. Woo, C. M. Dettmer, S. T.

Nguyen, C. J. Ellison, K. R. Shull, J. M. Torkelson, Macromolecules 2009, 42, 7863.

[6] C. Charbonneau, C. Chassenieux, O. Colombani, T. Nicolai, Macromolecules 2011, 44, 4487.

[7] S. Harrisson, F. Ercole, B. W. Muir, Polym. Chem. 2010, 1, 326.

[8] J. R. Brown, Y. Seo, S. W. Sides, L. M. Hall, Macromolecules 2017, 50, 5619.

[9] C. Guerrero-Sanchez, L. O'Brien, C. Brackley, D. J. Keddie, S. Saubern, J. Chiefari, Polym. Chem. 2013, 4, 1857.

[10] E. Lejeune, M. Drechsler, J. Jestin, A. H. E. Müller, C. Chassenieux, O. Colombani, Macromolecules 2010, 43, 2667.

[11] D. D. Bendejacq, V. Ponsinet, J. Phys. Chem. B 2008, 112, 7996.

[12] D. D. Bendejacq, V. Ponsinet, M. Joanicot, Langmuir 2005, 21, 1712.

[13] M. Y. Zaremski, D. I. Kalugin, V. B. Golubev, Polym. Sci. Series A 2009, 51, 103.

[14] K. Matyjaszewski, M. J. Ziegler, S. V. Arehart, D. Greszta, T. Pakula, J. Phys. Org. Chem. 2000, 13, 775.

[15] N. A. Lynd, A. J. Meuler, M. A. Hillmyer, Prog. Polym. Sci. 2008, 33, 875.

[16] G. Gody, P. B. Zetterlund, S. Perrier, S. Harrisson, Nature Commun. 2016, 7, 10514.

[17] M. D. Lefebvre, M. Olvera de la Cruz, K. R. Shull, Macromolecules 2004, 37, 1118.

[18] N. B. Tito, S. T. Milner, J. E. G. Lipson, Macromolecules 2010, 43, 10612.

[19] R. Wang, W. Li, Y. Luo, B.-G. Li, A.-C. Shi, S. Zhu, Macromolecules 2009, 42, 2275.

[20] A. V. Dobrynin, L. Leibler, Macromolecules 1997, 30, 4756.

[21] V. Ganesan, N. A. Kumar, V. Pryamitsyn, Macromolecules 2012, 45, 6281.

[22] X. Liu, M. Wang, S. Harrisson, A. Debuigne, J.-D. Marty, M. Destarac, ACS Sust.

Chem. Eng. 2017, 5, 9645.

[23] R. Yanez-Macias, I. Kulai, J. Ulbrich, T. Yildirim, P. Sungur, S. Hoeppener, R.

Guerrero-Santos, U. S. Schubert, M. Destarac, C. Guerrero-Sanchez, S. Harrisson, Polym. Chem. 2017, 8, 5023.

[24] K. J. Sykes, S. Harrisson, D. J. Keddie, Macromol. Chem. Phys. 2016, 217, 2310.

[25] P. H. M. Van Steenberge, D. R. D'Hooge, Y. Wang, M. J. Zhong, M. F. Reyniers, D.

Konkolewicz, K. Matyjaszewski, G. B. Marin, Macromolecules 2012, 45, 8519.

[26] A. M. Elsen, Y. C. Li, Q. X. Li, S. S. Sheiko, K. Matyjaszewski, Macromol. Rapid Commun. 2014, 35, 133.

[27] A. Clough, J. L. Sigle, A. Tapash, L. Gill, N. V. Patil, J. Zhou, J. L. White, Macromolecules 2014, 47, 2625.

[28] R. Hoogenboom, M. W. M. Fijten, S. Wijnans, A. M. J. van den Berg, H. M. L. Thijs, U. S. Schubert, J. Comb. Chem. 2006, 8, 145.

[29] R. Hoogenboom, H. M. L. Thijs, M. W. M. Fijten, B. M. van Lankvelt, U. S. Schubert, J. Polym. Sci. Part A: Polym. Chem. 2007, 45, 416.

[30] Y. Milonaki, E. Kaditi, S. Pispas, C. Demetzos, J. Polym. Sci. Part A: Polym. Chem.

2012, 50, 1226.

[31] M. Uchman, J. Hajduová, E. Vlassi, S. Pispas, M.-S. Appavou, M. Štěpánek, Eur.

Polym. J. 2015, 73, 212.

[32] E. Vlassi, S. Pispas, Macromol. Chem. Phys. 2015, $216,873$. 
[33] R. Hoogenboom, H. M. L. Lambermont-Thijs, M. J. H. C. Jochems, S. Hoeppener, C. Guerlain, C.-A. Fustin, J.-F. Gohy, U. S. Schubert, Soft Matter 2009, 5, 3590.

[34] R. Zhao, K. J. Shea, ACS Macro Lett. 2015, 4, 584.

[35] T. Hardeman, G. Koeckelberghs, Macromolecules 2015, 48, 6987.

[36] P. Xiang, Z. Ye, J. Polym. Sci. Part A: Polym. Chem. 2013, 51, 672.

[37] Y. Liu, W.-M. Ren, K.-K. He, X.-B. Lu, Nature Commun. 2014, 5, 5687.

[38] A. B. Chang, T.-P. Lin, N. B. Thompson, S.-X. Luo, A. L. Liberman-Martin, H.-Y.

Chen, B. Lee, R. H. Grubbs, J. Am. Chem. Soc. 2017, 139, 17683.

[39] C. M. Dettmer, M. K. Gray, J. M. Torkelson, S. T. Nguyen, Macromolecules 2004, 37, 5504.

[40] K. O. Kim, T.-L. Choi, Macromolecules 2013, 46, 5905.

[41] T.-P. Lin, A. B. Chang, H.-Y. Chen, A. L. Liberman-Martin, C. M. Bates, M. J. Voegtle, C. A. Bauer, R. H. Grubbs, J. Am. Chem. Soc. 2017, 139, 3896.

[42] M. D. Lefebvre, C. M. Dettmer, R. L. McSwain, C. Xu, J. R. Davila, R. J. Composto, S. T. Nguyen, K. R. Shull, Macromolecules 2005, 38, 10494.

[43] B.-S. Kim, H.-K. Lee, S. Jeong, J.-O. Lee, H.-j. Paik, Macromol. Res. 2011, 19, 1257.

[44] A. M. Elsen, Y. Li, Q. Li, S. S. Sheiko, K. Matyjaszewski, Macromol. Rapid Commun. 2014, 35, 133.

[45] K. Min, M. Li, K. Matyjaszewski, J. Polym. Sci. Part A: Polym. Chem. 2005, 43, 3616. [46] J. He, Y. Wang, Q. Lin, L. Chen, X. Zhou, J. Macromol. Sci., Part A 2009, 46, 405.

[47] B. Gu, A. Sen, Macromolecules 2002, 35, 8913.

[48] S. Qin, J. Saget, J. Pyun, S. Jia, T. Kowalewski, Macromolecules 2003, 36, 8969.

[49] C. Lefay, B. Charleux, M. Save, C. Chassenieux, O. Guerret, S. Magnet, Polymer 2006, 47, 1935.

[50] M. Zaremski, I. Eremeev, E. Garina, O. Borisova, B. Korolev, J. Polym. Res. 2017, 24, 151.

[51] C. Farcet, B. Charleux, R. Pirri, Macromol. Symp. 2002, 182, 249.

[52] E. Mignard, T. Leblanc, D. Bertin, O. Guerret, W. F. Reed, Macromolecules 2004, 37, 966.

[53] O. Borisova, L. Billon, M. Zaremski, B. Grassl, Z. Bakaeva, A. Lapp, P. Stepanek, O. Borisov, Soft Matter 2012, 8, 7649.

[54] D. I. Kalugin, M. Y. Zaremski, V. B. Golubev, E. S. Garina, Polym. Sci. Ser. B 2011, 53, 307.

[55] N. Cherifi, A. Issoulie, A. Khoukh, A. Benaboura, M. Save, C. Derail, L. Billon, Polym. Chem. 2011, 2, 1769.

[56] Z. Cernochova, A. Bogomolova, O. V. Borisova, S. K. Filippov, P. Cernoch, L. Billon, O. V. Borisov, P. Stepanek, Soft Matter 2016, 12, 6788.

[57] M. Hurtgen, A. Debuigne, C.-A. Fustin, C. Jérôme, C. Detrembleur, Macromolecules 2011, 44, 4623.

[58] C. Guerrero-Sanchez, S. Harrisson, D. J. Keddie, Macromol. Symp. 2013, 325-326, 38. [59] A. Tselepy, T. L. Schiller, S. Harrisson, C. Guerrero-Sanchez, G. Moad, D. J. Keddie, Macromolecules 2018, 51, 410.

[60] X. Tang, J. Han, Z. Zhu, X. Lu, H. Chen, Y. Cai, Polym. Chem. 2014, 5, 4115.

[61] T. Ribaut, P. Lacroix-Desmazes, B. Fournel, S. Sarrade, J. Polym. Sci. Part A: Polym. Chem. 2009, 47, 5448.

[62] F. Lin, M. Wang, Y. Pan, T. Tang, D. Cui, B. Liu, Macromolecules 2017, 50, 849.

[63] F. R. Mayo, F. M. Lewis, J. Am. Chem. Soc. 1944, 66, 1594.

[64] I. Skeist, J. Am. Chem. Soc. 1946, 68, 1781.

[65] H.-i. Lee, K. Matyjaszewski, S. Yu, S. S. Sheiko, Macromolecules 2005, 38, 8264. 
[66] F. Ercole, N. Malic, S. Harrisson, T. P. Davis, R. A. Evans, Macromolecules 2010, 43, 249.

[67] E. V. Vasilyeva, N. A. Kopylova, S. D. Zaitsev, Y. D. Semchikov, Polym. Sci. Ser. B 2011, 53, 491.

[68] S. Harrisson, X. Liu, J.-N. Ollagnier, O. Coutelier, J.-D. Marty, M. Destarac, Polymers 2014, 6, 1437.

[69] M. Destarac, W. Bzducha, D. Taton, I. Gauthier-Gillaizeau, S. Z. Zard, Macromol. Rapid Commun. 2002, 23, 1049.

[70] E. Read, A. Guinaudeau, D. James Wilson, A. Cadix, F. Violleau, M. Destarac, Polym. Chem. 2014, 5, 2202.

[71] G. Moad, R. T. A. Mayadunne, E. Rizzardo, M. Skidmore, S. H. Thang, Macromol. Symp. 2003, 192, 1.

[72] G. Moad, E. Rizzardo, S. H. Thang, Aust. J. Chem. 2005, 58, 379.

[73] J. Kim, R. W. Sandoval, C. M. Dettmer, S. T. Nguyen, J. M. Torkelson, Polymer 2008, 49, 2686.

[74] J. Kim, M. K. Gray, H. Zhou, S. T. Nguyen, J. M. Torkelson, Macromolecules 2005, 38, 1037.

[75] R. K. Roy, J.-F. Lutz, J. Am. Chem. Soc. 2014, 136, 12888.

[76] R. Kakuchi, M. Zamfir, J.-F. Lutz, P. Theato, Macromol. Rapid Commun. 2012, 33, 54.

[77] O. V. Borisova, L. Billon, Z. Cernochova, A. Lapp, P. Stepanek, O. V. Borisov, Macromol. Symp. 2015, 348, 25.

[78] A. I. Buzin, M. Pyda, P. Costanzo, K. Matyjaszewski, B. Wunderlich, Polymer 2002, 43, 5563.

[79] Z. Zheng, X. Gao, Y. Luo, S. Zhu, Macromolecules 2016, 49, 2179.

[80] Y. Guo, J. Zhang, P. Xie, X. Gao, Y. Luo, Polym. Chem. 2014, 5, 3363.

[81] S. Jouenne, J. A. González-León, A.-V. Ruzette, P. Lodefier, S. Tencé-Girault, L.

Leibler, Macromolecules 2007, 40, 2432.

[82] Q. Zhang, P. Wilson, Z. Li, R. McHale, J. Godfrey, A. Anastasaki, C. Waldron, D. M. Haddleton, J. Am. Chem. Soc. 2013, 135, 7355.

[83] Q. Zhang, J. Collins, A. Anastasaki, R. Wallis, D. A. Mitchell, C. R. Becer, D. M. Haddleton, Angew. Chem. Int. Ed. 2013, 52, 4435.

[84] A. Anastasaki, C. Waldron, P. Wilson, C. Boyer, P. B. Zetterlund, M. R. Whittaker, D. Haddleton, ACS Macro Lett. 2013, 2, 896.

[85] F. Alsubaie, A. Anastasaki, P. Wilson, D. M. Haddleton, Polym. Chem. 2015, 6, 406.

[86] A. Anastasaki, V. Nikolaou, N. W. McCaul, A. Simula, J. Godfrey, C. Waldron, P.

Wilson, K. Kempe, D. M. Haddleton, Macromolecules 2015, 48, 1404.

[87] A. Anastasaki, V. Nikolaou, G. S. Pappas, Q. Zhang, C. Wan, P. Wilson, T. P. Davis, M. R. Whittaker, D. M. Haddleton, Chem. Sci. 2014, 5, 3536.

[88] G. Gody, T. Maschmeyer, P. B. Zetterlund, S. Perrier, Nature Commun. 2013, 4, 2505.

[89] G. Gody, T. Maschmeyer, P. B. Zetterlund, S. Perrier, Macromolecules 2014, 47, 3451.

[90] G. Gody, R. Barbey, M. Danial, S. Perrier, Polym. Chem. 2015, 6, 1502.

[91] N. G. Engelis, A. Anastasaki, G. Nurumbetov, N. P. Truong, V. Nikolaou, A. Shegiwal, M. R. Whittaker, T. P. Davis, D. M. Haddleton, Nature Chem. 2016, 9, 171.

[92] M. Rodlert, E. Harth, I. Rees, C. J. Hawker, J. Polym. Sci. Part A: Polym. Chem. 2000, $38,4749$.

[93] T. Nicolai, O. Colombani, C. Chassenieux, Soft Matter 2010, 6, 3111.

[94] X. Zhang, F. Boisson, O. Colombani, C. Chassenieux, B. Charleux, Macromolecules 2014, 47, 51.

[95] M. J. Ziegler, K. Matyjaszewski, Macromolecules 2001, 34, 415.

[96] S. V. Arehart, K. Matyjaszewski, Macromolecules 1999, 32, 2221. 
[97] K. Min, J. Kwon Oh, K. Matyjaszewski, J. Polym. Sci. Part A: Polym. Chem. 2007, 45, 1413.

[98] Y.-N. Zhou, Z.-H. Luo, Polym. Chem. 2013, 4, 76.

[99] H. G. Börner, D. Duran, K. Matyjaszewski, M. da Silva, S. S. Sheiko, Macromolecules 2002, 35, 3387.

[100] X. Sun, Y. Luo, R. Wang, B.-G. Li, B. Liu, S. Zhu, Macromolecules 2007, 40, 849.

[101] R. Wang, Y. Luo, B. Li, X. Sun, S. Zhu, Macromol. Theory Simul. 2006, 15, 356.

[102] X. Sun, Y. Luo, R. Wang, B.-G. Li, S. Zhu, AIChE J. 2008, 54, 1073.

[103] L. Wang, L. J. Broadbelt, Macromolecules 2009, 42, 8118.

[104] K. Karaky, E. Pere, C. Pouchan, J. Desbrieres, C. Derail, L. Billon, Soft Matter 2006, 2, 770 .

[105] K.-I. Seno, I. Tsujimoto, S. Kanaoka, S. Aoshima, J. of Polym. Sci. Part A: Polym. Chem. 2008, 46, 6444.

[106] W. Yuan, M. M. Mok, J. Kim, C. L. H. Wong, C. M. Dettmer, S. T. Nguyen, J. M. Torkelson, K. R. Shull, Langmuir 2010, 26, 3261.

[107] W. Yuan, E. J. Laprade, K. J. Henderson, K. R. Shull, Soft Matter 2014, 10, 1142.

[108] M. M. Mok, J. Kim, J. M. Torkelson, J. Polym. Sci. Part B: Polym. Phys. 2008, 46, 48.

[109] M. M. Mok, J. M. Torkelson, J. Polym. Sci. Part B: Polym. Phys. 2012, 50, 189.

[110] M. M. Mok, S. Pujari, W. R. Burghardt, C. M. Dettmer, S. T. Nguyen, C. J. Ellison, J. M. Torkelson, Macromolecules 2008, 41, 5818.

[111] J. Kim, H. Zhou, S. T. Nguyen, J. M. Torkelson, Polymer 2006, 47, 5799.

[112] K. Karaky, G. Clisson, G. Reiter, L. Billon, Macromol. Chem. Phys. 2008, 209, 715.

[113] Y. Tao, J. Kim, J. M. Torkelson, Polymer 2006, 47, 6773.

[114] K. Karaky, L. Billon, C. Pouchan, J. Desbrières, Macromolecules 2007, 40, 458.

[115] K. Karaky, C. Derail, G. Reiter, L. Billon, Macromol. Symp. 2008, $267,31$.

[116] J. A. Amonoo, A. Li, G. E. Purdum, M. E. Sykes, B. Huang, E. F. Palermo, A. J.

McNeil, M. Shtein, Y.-L. Loo, P. F. Green, J. Mater. Chem. A 2015, 3, 20174.

[117] E. F. Palermo, A. J. McNeil, Macromolecules 2012, 45, 5948.

[118] E. F. Palermo, H. L. van der Laan, A. J. McNeil, Polym. Chem. 2013, 4, 4606.

[119] E. F. Palermo, S. B. Darling, A. J. McNeil, J. Mater. Chem. C 2014, 2, 3401.

[120] K. C. Gallow, Y. K. Jhon, J. Genzer, Y.-L. Loo, Polymer 2012, 53, 1131.

[121] S. B. Lee, A. J. Russell, K. Matyjaszewski, Biomacromolecules 2003, 4, 1386.

[122] G. Zhang, J. Jiang, Q. Zhang, F. Gao, X. Zhan, F. Chen, Langmuir 2016, 32, 1380.

[123] W. Steinhauer, R. Hoogenboom, H. Keul, M. Moeller, Macromolecules 2013, 46, 1447.

[124] S. Saubern, X. Nguyen, V. Nguyen, J. Gardiner, J. Tsanaktsidis, J. Chiefari, Macromol.

React. Eng. 2017, 11, 1600065.

[125] S. Okabe, K.-I. Seno, S. Kanaoka, S. Aoshima, M. Shibayama, Macromolecules 2006, $39,1592$.

[126] S. Okabe, K.-I. Seno, S. Kanaoka, S. Aoshima, M. Shibayama, Polymer 2006, 47, 7572.

[127] S. Okabe, C. Fuse, S. Sugihara, S. Aoshima, M. Shibayama, Physica B: Condensed Matter 2006, 385-386, 756.

[128] K.-I. Seno, I. Tsujimoto, T. Kikuchi, S. Kanaoka, S. Aoshima, J. Polym. Sci. Part A:

Polym. Chem. 2008, 46, 6151.

[129] X. Li, W.-J. Wang, F. Weng, B.-G. Li, S. Zhu, Ind. Eng. Chem. Res. 2014, 53, 7321.

[130] Y.-N. Zhou, J.-J. Li, Z.-H. Luo, J. Polym. Sci. Part A: Polym. Chem. 2012, 50, 3052.

[131] D. D'hooge, P. Van Steenberge, M.-F. Reyniers, G. Marin, Polymers 2014, 6, 1074.

[132] P. Derboven, P. H. M. V. Steenberge, J. Vandenbergh, M. F. Reyniers, T. Junkers, D.

R. D'hooge, G. B. Marin, Macromol. Rapid Commun. 2015, 36, 2149. 
[133] B. J. Reizman, K. F. Jensen, Acc. Chem. Res. 2016, 49, 1786.

[134] K. Nakatani, T. Terashima, M. Sawamoto, J. Am. Chem. Soc. 2009, 131, 13600.

[135] K. Nakatani, Y. Ogura, Y. Koda, T. Terashima, M. Sawamoto, J. Am. Chem. Soc. 2012, $134,4373$.

[136] Y. Ogura, T. Terashima, M. Sawamoto, Macromolecules 2017, 50, 822.

[137] T. Terashima, M. Sawamoto, "Sequence-Regulated Polymers via Living Radical Polym.ization: From Design to Properties and Functions", in Sequence-Controlled Polymers: Synthesis, Self-Assembly, and Properties, J.-F. Lutz, T.Y. Meyer, M. Ouchi, and M.

Sawamoto, Eds., American Chemical Society, 2014, p. 255.

[138] Y. Ogura, T. Terashima, M. Sawamoto, Polym. Chem. 2017, 8, 2299.

[139] Y. Ogura, M. Takenaka, M. Sawamoto, T. Terashima, Macromolecules 2018, 51, 864. [140] Y. Ogura, M. Artar, A. R. A. Palmans, M. Sawamoto, E. W. Meijer, T. Terashima, Macromolecules 2017, 50, 3215.

[141] C. Fu, B. Yang, C. Zhu, S. Wang, Y. Zhang, Y. Wei, L. Tao, Polym. Chem. 2013, 4, 5720 .

[142] X. Gu, L. Zhang, Y. Li, W. Zhang, J. Zhu, Z. Zhang, X. Zhu, Polym. Chem. 2018, 9, 1571 .

[143] D. J. Arriola, E. M. Carnahan, P. D. Hustad, R. L. Kuhlman, T. T. Wenzel, Science 2006, $312,714$.

[144] F. Dutertre, O. Boyron, B. Charleux, C. Chassenieux, O. Colombani, Macromol. Rapid Commun. 2012, 33, 753.

[145] C. Charbonneau, C. Chassenieux, O. Colombani, T. Nicolai, Macromolecules 2012, 45, 1025.

[146] C. Charbonneau, C. Chassenieux, O. Colombani, T. Nicolai, Phys. Rev. E 2013, 87, 062302.

[147] O. V. Borisov, E. B. Zhulina, F. A. M. Leermakers, A. H. E. Müller, "Self-Assembled Structures of Amphiphilic Ionic Block CoPolym.s: Theory, Self-Consistent Field Modeling and Experiment", in Self Organized Nanostructures of Amphiphilic Block Copolymers I, A.H.E. Müller and O. Borisov, Eds., Springer Berlin Heidelberg, Berlin, Heidelberg, 2011, p. 57.

[148] A. Halperin, S. Alexander, Macromolecules 1989, 22, 2403.

[149] Q. T. Pham, W. B. Russel, J. C. Thibeault, W. Lau, Macromolecules 1999, 32, 5139.

[150] C. Tsitsilianis, Soft Matter 2010, 6, 2372.

[151] O. Borisova, L. Billon, M. Zaremski, B. Grassl, Z. Bakaeva, A. Lapp, P. Stepanek, O.

Borisov, Soft Matter 2011, 7, 10824.

[152] A. Shedge, O. Colombani, T. Nicolai, C. Chassenieux, Macromolecules 2014, 47, 2439.

[153] C. Charbonneau, M. M. De Souza Lima, C. Chassenieux, O. Colombani, T. Nicolai, Phys. Chem. Chem. Phys. 2013, 15, 3955.

[154] O. Colombani, E. Lejeune, C. Charbonneau, C. Chassenieux, T. Nicolai, J. Phys. Chem. B 2012, 116, 7560 .

[155] O. Colombani, M. Ruppel, M. Burkhardt, M. Drechsler, M. Schumacher, M.

Gradzielski, R. Schweins, A. H. E. Müller, Macromolecules 2007, 40, 4351.

[156] M. Jacquin, P. Muller, R. Talingting-Pabalan, H. Cottet, J. F. Berret, T. Futterer, O.

Théodoly, J. Coll. Interf. Sci. 2007, 316, 897.

[157] C. Zheng, H. Huang, T. He, Macromol. Rapid Commun. 2013, 34, 1654.

[158] J. Chen, J.-J. Li, Z.-H. Luo, J. Polym. Sci. Part A: Polym. Chem. 2013, 51, 1107.

[159] Y. Chen, Y. Zhang, Y. Wang, C. Sun, C. Zhang, J. Appl. Polym. Sci. 2013, 127, 1485.

[160] Y. Zhao, Y.-W. Luo, B.-G. Li, S. Zhu, Langmuir 2011, 27, 11306.

[161] C. Zheng, H. Huang, T. He, Macromol. Rapid Commun. 2014, 35, 309. 
[162] E. S. Gil, S. M. Hudson, Prog. Polym. Sci. 2004, 29, 1173.

[163] S. Abbas, Z. Li, Hassan, T. P. Lodge, Macromolecules 2007, 40, 4048.

[164] K. Iyama, T. Nose, Polymer 1998, 39, 651.

[165] T. Ribaut, J. Oberdisse, B. Annighofer, I. Stoychev, B. Fournel, S. Sarrade, P. Lacroix-

Desmazes, Soft Matter 2009, 5, 4962.

[166] N. Merlet-Lacroix, E. Di Cola, M. Cloitre, Soft Matter 2010, 6, 984.

[167] P. Suárez, L. Rojo, Á. González-Gómez, J. S. Román, Macromol. BioSci. 2013, 13, 1174.

[168] T. Ribaut, J. Oberdisse, B. Annighofer, B. Fournel, S. Sarrade, H. Haller, P. LacroixDesmazes, J. Phys. Chem. B 2011, 115, 836.

[169] K. R. Shull, Macromolecules 2002, 35, 8631.

[170] C. L. H. Wong, J. Kim, C. B. Roth, J. M. Torkelson, Macromolecules 2007, 40, 5631.

[171] R. W. Sandoval, D. E. Williams, J. Kim, C. B. Roth, J. M. Torkelson, J. Polym. Sci.

Part B: Polym. Phys. 2008, 46, 2672.

[172] K. C. Gallow, Y. K. Jhon, W. Tang, J. Genzer, Y.-L. Loo, J. Polym. Sci. Part B:

Polym. Phys. 2011, 49, 629.

[173] R. París, J. L. De la Fuente, J. Polym. Sci. Part B: Polym. Phys. 2007, 45, 1845.

[174] T. Pakula, K. Matyjaszewski, Macromol. Theory Simul. 1996, 5, 987.

[175] K. Wylie, I. Bennett, M. Maric, Soft Matter 2017, 13, 2836.

[176] M. M. Mok, C. J. Ellison, J. M. Torkelson, Macromolecules 2011, 44, 6220.

[177] Y. Inoue, J. Watanabe, M. Takai, S.-i. Yusa, K. Ishihara, J. Polym. Sci. Part A: Polym. Chem. 2005, 43, 6073.

[178] J. Kim, M. M. Mok, R. W. Sandoval, D. J. Woo, J. M. Torkelson, Macromolecules 2006, 39, 6152.

[179] G. Zhang, Q. Zhang, Q. Wang, X. Zhan, F. Chen, J. Appl. Polym. Sci. 2016, 133, 42936.

[180] C. L. H. Wong, J. Kim, J. M. Torkelson, J. Polym. Sci. Part B: Polym. Phys. 2007, 45, 2842.

[181] J. Zhang, J. Li, L. Huang, Z. Liu, Polym. Chem. 2013, 4, 4639.

[182] W. Jakubowski, A. Juhari, A. Best, K. Koynov, T. Pakula, K. Matyjaszewski, Polym. 2008, 49, 1567.

[183] J. Zhang, R. Deubler, M. Hartlieb, L. Martin, J. Tanaka, E. Patyukova, P. D. Topham, F. H. Schacher, S. Perrier, Macromolecules 2017, 50, 7380.

[184] M. Z. Slimani, A. J. Moreno, G. Rossi, J. Colmenero, Macromolecules 2013, 46, 5066.

[185] M. M. Mok, J. Kim, S. R. Marrou, J. M. Torkelson, Eur. Phys. J. E 2010, 31, 239.

[186] M. M. Mok, K. A. Masser, J. Runt, J. M. Torkelson, Macromolecules 2010, 43, 5740.

[187] M. K. Gray, H. Zhou, S. T. Nguyen, J. M. Torkelson, Polymer 2004, 45, 4777.

[188] H. Wang, H. Zhou, Y. Chen, C. Zhang, Colloid. Polym. Sci. 2014, 292, 2803.

[189] R. Hoogenboom, H. M. L. Thijs, D. Wouters, S. Hoeppener, U. S. Schubert,

Macromolecules 2008, 41, 1581.

[190] J.-S. Park, K. Kataoka, Macromolecules 2006, 39, 6622.

[191] Y. Luo, Y. Guo, X. Gao, B.-G. Li, T. Xie, Adv. Mater. 2013, 25, 743.

[192] E. Lee, D. Kim, J. Yoon, ACS Appl. Mater. Interf. 2016, 8, 26359.

[193] X. Yang, Y. Guo, X. Luo, N. Zheng, T. Ma, J. Tan, C. Li, Q. Zhang, J. Gu, Compos.

Sci. Technol. 2018, 164, 59.

[194] Y. Li, G. Xu, Y. Guo, T. Ma, X. Zhong, Q. Zhang, J. Gu, Compos. Part A: Appl. Sci. Manuf. 2018, 107, 570.

[195] C. Liang, P. Song, H. Gu, C. Ma, Y. Guo, H. Zhang, X. Xu, Q. Zhang, J. Gu, Compos. Part A: Appl. Sci. Manuf. 2017, 102, 126. 
[196] X. Yang, L. Tang, Y. Guo, C. Liang, Q. Zhang, K. Kou, J. Gu, Compos. Part A: Appl. Sci. Manuf. 2017, 101, 237.

[197] C. Koning, M. Van Duin, C. Pagnoulle, R. Jerome, Prog. Polym. Sci. 1998, 23, 707.

[198] D. Sun, J. Cho, Langmuir 2014, 30, 6596.

[199] H. V. Penfold, S. J. Holder, B. E. Mkenzie, Polymer 2010, 51, 1904.

[200] C. Lefay, M. Save, B. Charleux, S. Magnet, Aust. J. Chem. 2006, 59, 544.

[201] Y. Guo, X. Gao, Y. Luo, J. Polym. Sci. Part B: Polym. Phys. 2015, 53, 860.

[202] B. M. Williams, V. Barone, B. D. Pate, J. E. Peralta, Comput. Mater. Sci. 2015, 96, 69.

[203] P. E. Stallworth, J. J. Fontanella, M. C. Wintersgill, C. D. Scheidler, J. J. Immel, S. G.

Greenbaum, A. S. Gozdz, J. Power Sources 1999, 81-82, 739.

[204] A. Arya, A. L. Sharma, Ionics 2017, 23, 497.

[205] W. H. Meyer, Adv. Mater. 1998, 10, 439.

[206] L. Couvreur, WO2010/018344.

[207] S. Magnet, O. Guerret, C. Lefay, B. Charleux, WO2006/066971.

[208] B. Goebelt, K. Haubennestel, U. Krappe, P. D. Valentina, US 2004/0143035.

[209] J. Weidmann, L. Frunz, J. Zimmermann, WO2017/050900.

[210] J. Weidmann, J. Zimmermann, WO2017/050907.

[211] J. M. Rokowski, A. E. Evans, US20160369122.

[212] Y. Zhang, Q. Duan, K. Wei, Y. Liu, H. Sun, WO2018/000804.

[213] M. Scherer, J. Souchik, J. M. Bollinger, CA2396681.

[214] S. C. Schmidt, P. A. Callais, N. E. Macy, J. S. Ness, US2011/0301298.

[215] O. Guerret, US2006/0058467.

[216] S. Magnet, H. Hediger, O. Guerret, WO2010/031973.

[217] N. Mougin, US2004/0180019.

[218] J. Gawtrey, N. Mougin, US2007/0086959.

[219] J. Gawtrey, N. Mougin, I. Rollat, US2007/0128127.

[220] S. Xavier, V. Marco, FR2936147.

[221] M. Benoit, S. Xavier, H. Christophe, FR2936148.

[222] C. Farcet, US2014/0227210.

[223] C. Farcet, WO2006/003317.

[224] K. Nakada, Y. Morishita, US2016/0122603. 